\title{
WILEY-VCH
}

"This is an Accepted Manuscript of an article published by Macromol. React. Eng. (MRE), of Wiley, accepted on April 2, 2020; doi: 10.1002/mren.202000004"

\section{Straightforward Synthesis and Evaluation of Polymeric Sensing Materials for Acetone Detection}

Alison J. Scott, Noushin Majdabadifarahani, Katherine M. E. Stewart, Thomas A. Duever, Alexander Penlidis*

Happy $60^{\text {th }}$, JBPS!

Dr. A. J. Scott, N. Majdabadifarahani, Prof. A. Penlidis

Institute for Polymer Research, Department of Chemical Engineering, University of Waterloo, 200 University Avenue West, Waterloo, Ontario, N2L 3G1, Canada

E-mail: penlidis@uwaterloo.ca

Prof. K. M. E. Stewart

Department of Chemistry and Physics, Troy University, 600 University Avenue, Troy, Alabama, 36082, USA

Prof. T. A. Duever

Department of Chemical Engineering, Ryerson University, 350 Victoria Street, Toronto, Ontario, M5B 2K3, Canada

Keywords: acetone, polyaniline, polypyrrole, sensing materials, metal oxides

Three polymeric materials (polyaniline, polypyrrole, and poly(methyl methacrylate)) have been selected, prepared and evaluated for potential use in acetone sensing (for possible diabetes-related applications). Of the materials studied, polyaniline and polypyrrole showed the most promise. Polypyrrole allowed for more acetone sorption (i.e., higher concentration of acetone sorbed), but did not distinguish between different target analytes (that is, it was not selective). A material's ability to distinguish between several gas analytes simultaneously (in a gas mixture) is rarely evaluated; selectivity is typically based on a 'one-analyte-at-a-time' investigation. However, comparison of acetone sorption (in one experimental test) and interferent sorption (in a complementary experimental test) does not consider interactions that might occur between gas analytes; this motivates the sorption analysis of gas mixtures that is shown in this work. The most promising results were obtained when polyaniline or 


\section{WILEY-VCH}

polypyrrole was exposed to acetone-rich gas mixtures with low amounts of acetaldehyde, ethanol and benzene (interferent gases). Polymer doping using three metal oxides $\left(\mathrm{SnO}_{2}, \mathrm{WO}_{3}\right.$ and $\mathrm{ZnO}$ ) was also investigated, but metal oxide addition had a limited effect on the sorption performance. This was true for all three metal oxides, regardless of the amount of doping (over the range studied; up to $20 \mathrm{wt} \%$ ).

\section{Introduction}

Diabetes mellitus, generally called diabetes, is a series of metabolic diseases in which the affected persons experience high blood sugar levels over long periods of time. Type 1 diabetes is caused by the pancreas' inability to produce enough insulin, whereas type 2 diabetes stems from an insulin resistance, which typically builds up over time. According to a recent report by the International Diabetes Federation, approximately 463 million people worldwide live with diabetes, and over $50 \%$ are undiagnosed. ${ }^{[1]}$ Diabetes research and treatment are well-developed in North America, but there is still a need for low cost, fast responding diagnosis and treatment methods, especially for developing countries.

When blood glucose levels are high, a person's breath often smells 'sweet'. This is largely due to elevated levels of ketones (namely acetone, acetoacetate and 3- $\beta$-hydroxybutyrate) that are produced as an alternative energy source, since the body cannot process the glucose that is present (this is a result of low insulin or insulin resistance). All three of the ketones listed above will increase in concentration, but acetone is by far the most volatile. Thus, it can be detected in a person's breath much more easily than acetoacetate or 3- $\beta$-hydroxybutyrate. ${ }^{[2]}$ Over the past 60 years, a variety of studies have been performed in an attempt to link breath acetone concentration to blood glucose levels. In effect, over 40 different investigations 


\section{WILEY-VCH}

(involving over 3,000 human subjects) have confirmed that breath acetone concentration can be used as a biomarker for diabetes mellitus. ${ }^{[3]}$

Increased acetone concentration within the human body can be exploited to develop noninvasive detection techniques for the diagnosis (and, eventually, potential control) of high blood glucose levels experienced by people with diabetes. Several groups have investigated the possibility of using metals and metal oxides as breath acetone sensors, with some success. ${ }^{[4-17]}$ There have also been several studies that involved polymeric sensing materials and sensing arrays (including these references ${ }^{[18-33]}$ ), but there is still room for improvement. Polymeric sensing materials typically provide better selectivity than metals and metal oxides and have the added advantage of lower cost and customization (tailorability). ${ }^{[34]}$ However, good acetone selectivity continues to be elusive (and is rarely considered), and many polymeric sensing materials that have been investigated require extremely complex synthesis procedures (see, for example, the review by McQuade et al. ${ }^{[35]}$ ) .

\section{Background - Polymeric Materials for Acetone Sensing}

The ability to use polymers as sensing materials depends primarily on sensitivity and selectivity. The sensitivity of a sensor (or sensing material) is related to the lowest discernible concentration that can be measured. Lower concentrations are preferable, indicative of a sensitive sensor or sensing material. It has been reported previously that breath acetone ranges from $148 \mathrm{ppb}$ to $2744 \mathrm{ppb}$, and in an extreme case has reached $20 \mathrm{ppm} .{ }^{[2]}$ The challenge is to find materials that have a strong affinity towards the target analyte (that is, show high levels of sorption compared to other materials), but that can also sorb low concentrations (this is the sensitivity aspect). 
Selectivity measures how much the sensing material favours the target analyte over other possible interferents (at roughly equal concentrations), and can be calculated using Equation 1. The larger the ratio between acetone sorption and the interferent gas sorption, the more selective the material is towards acetone. As a general rule of thumb, a material is considered to be selective towards the target analyte (compared to some interferent) when the selectivity value is greater than $1.75 .^{[36]}$

$$
\text { Selectivity } \left.=\frac{[\text { Acetone }]_{\text {Sorbed }}}{[\text { Interferent }}\right]_{\text {Sorbed }}
$$

However, it is important to note that good selectivity towards acetone with respect to one interferent does not guarantee good selectivity when other (chemically different) interferent gases are present. Therefore, as shown in Table 1, researchers often choose to evaluate a material's selectivity towards acetone in the presence of several interferents. ${ }^{[18,20,23,24,27,28]}$

Table 1. Breath Acetone Detection Studies; Summary of Sensing Materials

\begin{tabular}{|c|c|c|c|c|}
\hline Ref. & $\begin{array}{l}\text { Sensing Material (and } \\
\text { dopant, if applicable) }\end{array}$ & Sensor Type & $\begin{array}{l}\text { Detection Limit (lowest } \\
\text { reported concentration) }\end{array}$ & Selectivity \\
\hline [18] & $\begin{array}{l}\text { PMMA and PVAc thin films } \\
\text { (prepared via plasma } \\
\text { polymerization and solution } \\
\text { casting) }\end{array}$ & QCM & $5 \%$ activity & $\begin{array}{l}\text { Good selectivity with } \mathrm{MeOH} \text {, hexane } \\
\text { and water; better selectivity at higher } \\
\text { concentrations }\end{array}$ \\
\hline [19] & $\begin{array}{c}\text { PPy/PMMA blend doped with } \\
\qquad \alpha-\mathrm{NS}^{-}\end{array}$ & Resistive & $\begin{array}{c}\text { Saturated } \\
\text { (30.3 vol. \%) }\end{array}$ & Acetic Acid (2.0-2.6) \\
\hline [20] & $\begin{array}{l}\text { PMMA composites with } \\
\text { S1: multiwalled CNTs and } \\
\text { S2: surface-modified } \\
\text { multiwalled CNTs }\end{array}$ & Resistive & -- & $\begin{array}{l}\text { Dichloromethane (S1: 0.64, S2: 0.10); } \\
\text { Chloroform: (S1: 0.84, S2: 0.21); } \\
\text { MeOH: (S1: 1.48, S2: 1.87); Ethyl } \\
\text { acetate (S1: 2.85, S2: 2.80); Toluene } \\
\text { (S1: 2.83, S2: 80.77); Hexane (S1 \& } \\
\text { S2: no response) }\end{array}$ \\
\hline
\end{tabular}


WILEY-VCH

\begin{tabular}{|c|c|c|c|c|}
\hline$[21]$ & $\begin{array}{l}\text { 3-enzyme system: } \\
\text { s-ADH, LDH, PO }\end{array}$ & $\begin{array}{l}\text { Ampero-metric } \\
\text { (via formation } \\
\text { of } \mathrm{H}_{2} \mathrm{O}_{2} \text { ) }\end{array}$ & $0.2 \mathrm{ppm}$ & $\begin{array}{l}\text { Good selectivity with EtOH; poor } \\
\text { selectivity for ketones and aldehydes } \\
\text { (data not reported) }\end{array}$ \\
\hline$[22]$ & $\begin{array}{c}\text { PPy sensor arrays: } \\
4 \text { sensing materials varying in } \\
\text { thickness \& resistance }\end{array}$ & Resistive & $50 \mathrm{ppm}$ & $\begin{array}{c}\text { EtOH (S1: } 0.95-1.4 ; \\
\text { S2: } 1.0-1.6 ; \\
\text { S3: } 1.2-1.6 ; \\
\text { S4: } 0.93-1.3)\end{array}$ \\
\hline [23] & $\begin{array}{l}\text { PECH; } 2 \text { sensing materials } \\
\text { varying in thickness }\end{array}$ & QCM & $0.16 \mathrm{ppm}$ & $\begin{array}{c}\text { DMMP (S1: 2.1, S2: 5.2); } \\
\text { EtOH (S1: 4.7, S2: 6.3); Hexane (S1: } \\
\text { 3.7, S2: 6.8) }\end{array}$ \\
\hline$[24]$ & $\begin{array}{l}\text { PMN-PT coated with thin film } \\
\text { PMMA }\end{array}$ & Resonant & $\begin{array}{c}15000 \text { ppm } \\
\text { (high sensitivity) }\end{array}$ & $\begin{array}{l}\text { Acetone, } \mathrm{MeOH} \text { and isopropyl alcoho } \\
\text { gave distinct responses, but no } \\
\text { selectivity reported }\end{array}$ \\
\hline$[25]$ & $\begin{array}{l}\text { Poly(EDOT-co-TAA) films } \\
\text { doped with Pd NPs }\end{array}$ & Resistive & $\begin{array}{l}167 \text { ppm (measured) } \\
10 \text { ppm (projected) }\end{array}$ & $\begin{array}{c}\text { Toluene } \\
\text { (no sensor response for [toluene] }< \\
304 \mathrm{ppm} \text { ) }\end{array}$ \\
\hline$[26]$ & $\begin{array}{l}\text { ZnO quantum dots embedded } \\
\text { in PVP }\end{array}$ & Resistive & 100 ppm & -- \\
\hline [27] & $\begin{array}{c}\text { PPy deposited by COC or } \\
\text { CVD; PPy(COC) doped with } \alpha- \\
\text { NS }^{-}\end{array}$ & Resistive & $\begin{array}{c}\text { PPy(COC): } \\
2983 \text { ppm; PPy(CVD): } \\
6010 \text { ppm }\end{array}$ & -- \\
\hline [27] & $\begin{array}{l}\text { PANI/PMMA and PANI } \\
\text { deposited by COC or IO; } \\
\text { PANI/PMMA(COC) doped } \\
\text { with } \mathrm{ClO}_{4}^{-} \text {and } \mathrm{SO}_{4}^{2-}\end{array}$ & Resistive & $\begin{array}{c}\text { PANI/PMMA (COC): } \\
132 \mathrm{ppm} \\
\text { PANI(IO): } \\
29 \mathrm{ppm}\end{array}$ & $\begin{array}{c}\text { For PANI/PMMA (COC): } \mathrm{O}_{2}, \mathrm{CO}_{2} \text {, } \\
\qquad \mathrm{H}_{2} \mathrm{O} \text { (cannot be calculated) }\end{array}$ \\
\hline$[28]$ & $\begin{array}{l}\text { NADPH-dependent carbonyl } \\
\text { reductase enzyme and Nafion } \\
\qquad\left(\mathrm{C}_{7} \mathrm{HF}_{13} \mathrm{O}_{5} \mathrm{~S} \mathrm{C}_{2} \mathrm{~F}_{4}\right)\end{array}$ & Ampero-metric & $\begin{array}{l}\text { Enzyme: no } \\
\text { improvement over bare } \\
\text { electrode; Nafion: better } \\
\text { response }\end{array}$ & $\begin{array}{l}\text { For Nafion: EtOH (1.2); } \\
\text { Formaldehyde (1.7); } \\
\text { MeOH (0.72); } \\
\mathrm{NH}_{4} \mathrm{OH}(0.34)\end{array}$ \\
\hline [29] & Chitosan & Resistive & $0.1 \mathrm{ppm}$ & $\mathrm{MeOH}(1.2-2.0)$ \\
\hline$[30]$ & PPy/PMMA/PEG composite & QCM & $290 \mathrm{ppm}$ & EtOH (data not reported) \\
\hline
\end{tabular}


WILEY-VCH

\begin{tabular}{|c|c|c|c|c|}
\hline [31] & $\begin{array}{l}\text { OV-275 and P25DMA doped } \\
\text { with } \mathrm{NiO}\end{array}$ & Capacitive & 625 ppm for both & $\begin{array}{l}\text { Benzene (OV-275: 6.7; P25DMA: } \\
0.26)\end{array}$ \\
\hline [32] & $\begin{array}{c}\text { PVDF-HFP composite sensors } \\
\text { with C65; } \\
\text { S1: PVDF-HFP/C65 } \\
\text { S2: multilayer with PVDF-HFP } \\
\text { and PVDF-HFP/C65 } \\
\text { S3: PVDF-HFP/C65/CNT }\end{array}$ & QCM & 42 ppm for all 3 & $\begin{array}{l}\text { EtOH (S1: 9.4, S2: 10.1, S3: 6.0) } \\
\text { Isoprene (S1: 17.5, S2: 11.5, S3: 11.9) } \\
\text { 2-ethylhexyl acetate (good selectivity, } \\
\text { cannot be calculated) }\end{array}$ \\
\hline [33] & $\begin{array}{l}\mathrm{PMMA} / \mathrm{Al}_{2} \mathrm{O}_{3} \text { thick film } \\
\text { composite }\end{array}$ & Resistive & -- & $\begin{array}{l}\text { Good selectivity with EtOH and } \\
\text { ammonia } \\
\text { (data not reported) }\end{array}$ \\
\hline \multicolumn{5}{|c|}{$\begin{array}{l}\text { Abbreviations: } \alpha \text {-NS- = } \alpha \text {-naphthalene sulfonate; C65 = carbon black; CNT = carbon nanotube; } \mathrm{COC} \text { = chemical oxidation casting; } \\
\text { CVD = chemical vapour deposition; DMMP = dimethyl methyl phosphonate; EtOH = ethanol; } \mathrm{OO}=\text { impregnated oxidation; } \mathrm{LDH}= \\
\text { lactate dehydrogenase; } \mathrm{MeOH}=\text { methanol; NADPH = nicotinamide adenine dinucleotide phosphate; NPs = nanoparticles; OV-275 = } \\
\text { highly polar siloxane-based polymer; P25DMA = poly(2,5-dimethyl aniline); PANI = polyaniline; PECH = polyepichlorohydrin; } \\
\text { PMMA = poly(methyl methacrylate); PMN-PT = lead magnesium niobate-lead titanate; PO = pyruvate oxidase; poly(EDOT-co- } \\
\text { TAA) = poly(3,4-ethylenedioxythiophene-co-thiophene-3-acetic acid); PPy = polypyrrole; PVDF-HFP = polyvinylidene fluoride } \\
\text { hexafluoropropylene; PVP = polyvinyl pyrrolidone; QCM = quartz crystal microbalance; s-ADH = secondary alcohol dehydrogenase }\end{array}$} \\
\hline
\end{tabular}

Table 1 provides an overview of the literature for acetone detection with polymeric materials, but it also highlights the challenges and limitations associated with the materials studied to date. In general, the reported selectivity towards acetone is low in the presence of several different interferent gases (including methanol, ${ }^{[28,29]}$ ethanol, ${ }^{[22,28]}$ ammonium hydroxide, ${ }^{[28]}$ and benzene ${ }^{[31]}$ ). For materials with higher selectivity, the polymers (and/or sensor preparation steps) are generally more complex. ${ }^{[23-26,28,31,32]}$ Therefore, there seems to be a tradeoff between selectivity and simplicity of synthesis.

An additional point of interest is that, in many studies, the target analyte is not considered alongside interferents (that is, the sensing material is not exposed to the target analyte and interferent gases simultaneously). Instead, selectivity is based on comparison of acetone sorption (in one experimental test) and interferent sorption (in a complementary experimental test). Take, for example, the work by Ruangchuay et $a l,{ }^{[19]}$ in which acetone sorption and 


\section{WILEY-VCH}

acetic acid sorption were compared. The polymeric sensing materials were exposed to either saturated acetone vapour (30.3 vol.\%) or saturated acetic acid vapour (2.0 vol.\%), and the sensor response was recorded in each case. Then, the selectivity of the materials was reported as the ratio between the acetone response and the acetic acid response. While this type of 'one-analyte-at-a-time' investigation is common, it does not consider any interactions that might occur between gas analytes. Also, in this case, two different gas concentrations are being compared; it makes sense that acetone yields a greater sensor response than acetic acid when it is present in a much higher concentration.

The motivation for the current study is to explore straightforward synthesis techniques for acetone sensing materials, to screen materials based on their affinity towards acetone, and then to consider the selectivity of materials towards acetone in the presence of other interferent gases. Rather than using a ‘one-analyte-at-a-time’ approach, candidate sensing materials can be exposed to several gases simultaneously. ${ }^{[3]}$ The materials selected for evaluation are described in Section 2.1.

\subsection{Consideration of Polymeric Materials}

In considering candidate polymers for sensing, it is important to first identify unique functional groups on the target analyte (acetone). For example, the polarity and the capability for hydrogen bonding should be exploited when selecting a sensing material for ketones. ${ }^{[38]}$ That is, sensing materials that will promote hydrogen bonding are desirable for acetone detection; polyaniline or polypyrrole may promote sorption via the - $\mathrm{NH}$ groups, while poly (vinyl alcohol) or poly (acrylic acid) may promote acetone sorption via the -OH groups. 


\section{WILEY-VCH}

One of the recommended techniques for selecting a sensing material is to compare the solubility parameters of the target analyte and the potential sensing materials. ${ }^{[39]}$ If the solubility parameters for the analyte and the sensing material are close in value, this indicates that the materials are likely to interact. Table 2 presents the solubility parameters of the target analyte (acetone), as well as the solubility parameters of some potential interferents. The table also includes sensing materials of interest, some of which will be discussed further shortly.

Table 2. Hildebrand Solubility Parameters for Target Analyte, Interferents, and Potential Sensing Materials (from ${ }^{[40]}$ unless otherwise stated)

\begin{tabular}{|l|r|l|r|}
\hline \multicolumn{1}{|c|}{ Analytes } & $\boldsymbol{\delta}\left[\mathbf{M P a}^{\mathbf{1}}{ }^{\prime}\right]$ & \multicolumn{1}{|c|}{ Sensing materials } & $\boldsymbol{\delta}\left[\mathbf{M P a}^{\mathbf{1}}\right]$ \\
\hline Acetaldehyde & 21.1 & Poly(acrylic acid) & $18.0-21.3$ \\
\hline Acetone & 20.3 & Polyaniline ${ }^{[41]}$ & 22.2 \\
\hline Acetic Acid & 20.7 & Polyisoprene & $16.2-20.5$ \\
\hline Benzene & 18.8 & Poly(methyl acrylate) ${ }^{[42]}$ & $19.9-21.3$ \\
\hline Chloroform & 19.0 & Poly(methyl methacrylate) ${ }^{[42]}$ & $18.6-26.2$ \\
\hline Dichloromethane & 19.8 & Polypyrrolel & 25.2 \\
\hline Ethanol & 26.0 & Poly(vinyl acetate) & $25.8-29.1$ \\
\hline Ethyl Acetate & 18.6 & Poly(vinyl alcohol $)^{[42]}$ & $19.2-22.1$ \\
\hline Hexane & 14.9 & Poly(vinyl chloride) & \\
\hline Methanol & 29.7 & & \\
\hline Toluene & 18.2 & & \\
\hline Water & 47.9 & & \\
\hline
\end{tabular}

This preliminary (and very general) assessment suggests that a number of polymeric materials are compatible in terms of solubility. However, solubility parameters should only be used as a general 'rule of thumb’ and should not be approached without critical thought. For example, poly(vinyl acetate) has a very promising range of solubility parameters relative to acetone. However, the $\mathrm{T}_{\mathrm{g}}$ for poly(vinyl acetate) is only around $30-35^{\circ} \mathrm{C},{ }^{[40]}$ which means that it will not be glassy at the operational temperature (human breath is generally around $35^{\circ} \mathrm{C}$ ) and is therefore not a viable candidate for breath acetone sensing. 


\section{WILEY-VCH}

Thus, from the list of candidate materials in Table 2, three polymer backbones were selected for further evaluation: polyaniline (PANI), polypyrrole (PPy), and poly(methyl methacrylate) (PMMA). All three polymers have been mentioned in the acetone sensing literature (with an array of properties and with varying degrees of success). Additionally, PANI, PPy and PMMA all have high glass transition temperatures (well above the operational temperature), exhibit potential for hydrogen bonding, and possess Hildebrand solubility parameters that are compatible with acetone.

Adding dopants to polymeric sensing materials has the potential to improve sensitivity and selectivity, electrical conductivity, thermal stability and mechanical integrity. Most dopants are metals and metal oxides, but in some cases acids can also be employed. Determination of potential dopants was informed by previous studies in which the materials were used for acetone detection (either as a dopant or as the primary sensing material); some of the most

widely used metal oxides for acetone detection are $\mathrm{SnO}_{2},{ }^{[4,10,14]} \mathrm{WO}_{3},{ }^{[7,11,12]}$ and $\mathrm{ZnO} .{ }^{[5,15,26]}$

\section{Experimental}

\subsection{Materials}

All materials were used as received. For the synthesis of polyaniline and polypyrrole, monomers (aniline and pyrrole) and initiators (ammonium persulfate, APS, and iron (III) chloride, $\mathrm{FeCl}_{3}$ ) were purchased from Sigma-Aldrich (Oakville, Ontario, Canada). Poly(methyl methacrylate) (PMMA) powder was purchased from Sigma-Aldrich (average molecular weight $\mathrm{Mw} \sim 15,000$ ). Metal oxide nanoparticles (used for doping) were also purchased from Sigma-Aldrich: $\mathrm{SnO}_{2}$ and $\mathrm{WO}_{3}$ came as powders (both $<100 \mathrm{~nm}$ nanoparticle 
size), and $\mathrm{ZnO}$ came in a 50\% solution with water (nanoparticle diameter $<100 \mathrm{~nm}$ ).

Deionized water was used for PANI and PPy synthesis; acetone (99\%) and ethanol (ACS grade) were used as received.

Analyte-containing gases used for sensing material evaluation were purchased from Praxair (Mississauga, Ontario, Canada). Separate gases containing pre-specified concentrations (on the ppm level) of acetaldehyde, ethanol, acetone and benzene were of standard grade, in nitrogen. Pure nitrogen (also from Praxair, 5.0 grade) was used to purge the samples prior to each sorption test.

\subsection{Synthesis}

Design of experiments was employed for the synthesis of polymeric materials: 3 polymer backbones (PANI, PPy and PMMA), 3 metal oxides $\left(\mathrm{SnO}_{2}, \mathrm{WO}_{3}\right.$ and $\left.\mathrm{ZnO}\right)$, and 3 dopant levels (5 wt\%, $10 \mathrm{wt} \%$ and $20 \mathrm{wt} \%$ dopant) were considered. Additionally, each polymer backbone was synthesized and evaluated without any dopant present. Therefore, 30 different polymer formulations were investigated.

\subsubsection{Synthesis of PANI}

Polyaniline (PANI) was synthesized by mixing aniline, ammonium persulfate (APS), and the metal oxide dopant (when applicable) in deionized water. PANI was synthesized in its pure (undoped) form, and doped with 5\%, 10\%, and 20\% (by weight) of the three metal oxides $\left(\mathrm{SnO}_{2}, \mathrm{WO}_{3}\right.$ and $\left.\mathrm{ZnO}\right)$. 


\section{WILEY-VCH}

As per Stewart et al., ${ }^{[44]}$ up to $0.4 \mathrm{~g}$ of monomer was added to $20 \mathrm{~mL}$ of deionized water and then mixed using a sonicator for 30 minutes. This solution was then cooled to $-1^{\circ} \mathrm{C}$ before the addition of a solution containing $1 \mathrm{~g}$ of APS in $5 \mathrm{~mL}$ of deionized water. The solution was mixed for one minute, and was then left for 6 hours to polymerize at $-1^{\circ} \mathrm{C}$. Upon completion of the reaction, the polymer was filtered out (Whatman \#5 filter paper) and the polymer was washed with ethanol or acetone at least three times.

When dopants were added to the sensing material, up to 20\% (by weight) of the metal oxide was suspended in the pre-polymerization solution. Then, the solution was cooled to $-1^{\circ} \mathrm{C}$ and APS was added to the system. The rest of the synthesis process was the same as above.

\subsubsection{Synthesis of PPy}

The synthesis procedure used for PPy was based on the work by Chitte et al. ${ }^{[4]}$ Polypyrrole (PPy) was synthesized by mixing pyrrole, $\mathrm{FeCl}_{3}$, and the dopant (when applicable) in deionized water. PPy was synthesized in its pure (undoped) form, and doped with 5\%, 10\%, and $20 \%$ (by weight) of the three metal oxides $\left(\mathrm{SnO}_{2}, \mathrm{WO}_{3}\right.$ and $\left.\mathrm{ZnO}\right)$.

Up to $0.4 \mathrm{~g}$ of monomer was added to $20 \mathrm{~mL}$ of deionized water and then mixed using a sonicator for 30 minutes. This solution was then cooled to $1^{\circ} \mathrm{C}$ before the addition of a $\mathrm{FeCl}_{3}$ solution. The $\mathrm{FeCl}_{3}$ solution was prepared using $5 \mathrm{~mL}$ distilled water; the initiator mass was selected such that the molar ratio of initiator to monomer was $2.4: 1$. The solution was mixed for one minute, and was then left for 4 hours to polymerize at $1^{\circ} \mathrm{C}$. Upon completion of the reaction, the polymer was filtered out (Whatman \#5 filter paper) and the polymer was washed with ethanol at least three times. 


\section{WILEY-VCH}

When dopants were added to the sensing material, up to 20\% (by weight) of the metal oxide was suspended in the pre-polymerization solution. Then, the solution was cooled to $1^{\circ} \mathrm{C}$ and $\mathrm{FeCl}_{3}$ was added to the system. The rest of the synthesis process is as described above.

\subsubsection{Preparation of PMMA}

Evaluation of PMMA as a sensing material for acetone employed PMMA (average molecular weight $\mathrm{Mw} \sim 15,000$ ) purchased from Sigma-Aldrich. PMMA was blended with 5\%, 10\% and 20\% (by weight) of the metal oxides described above. PMMA/metal oxide blends were created directly in the round bottom flasks that would later be used for sorption tests, which ensured that the percentage of metal oxides in each sample was as expected. In these cases, up to $0.1 \mathrm{~g}$ PMMA was dissolved in $10 \mathrm{~mL}$ acetone and stirred for 90 minutes at $100 \mathrm{rpm}$. Then, if metal oxides were used, they were weighed (to achieve the desired weight percentage) and rinsed into the PMMA solution. Mixing at 100 rpm continued for another 30 minutes, and then the flask was left (undisturbed) under ambient conditions for approximately 1 week. Once all acetone had evaporated, the samples were further dried at $50^{\circ} \mathrm{C}$ until a constant mass was reached.

\subsection{Characterization}

\subsubsection{Polymer Properties}

Scanning electron microscopy (SEM) and energy dispersive X-ray spectroscopy (EDX) were performed for select samples to evaluate the surface morphology and the polymer composition, respectively. SEM and EDX were both performed at the Waterloo Advanced 
Technology Laboratory (WATLAB) on a Zeiss UltraPlus FESEM and any non-conductive samples were gold coated prior to analysis.

\subsubsection{Sorption Properties}

The test set-up for sorption studies has been described previously by Stewart and Penlidis, ${ }^{[37]}$ and the overall schematic is shown in Figure 1. Individual polymer samples (each with a mass of $\sim 0.1 \mathrm{~g}$ ) were deposited into round bottom flasks and each polymer sample was purged with dry nitrogen for at least 1 hour prior to being exposed to the gas analyte(s). To measure the sorption, each polymeric sensing material was exposed to a gas (containing known concentrations of one or more analytes), and the amount of analyte that sorbed onto the sensing material was measured. All sorption measurements were taken at room temperature $\left(24^{\circ} \mathrm{C}\right)$ and approximately 15 psi.

The set-up uses a difference in gas concentration (before and after exposure to the sensing material) to establish how much of the target analyte has been sorbed. Prior to exposure, a 'blank’ run is analyzed using a highly specialized Varian 450 gas chromatograph (GC) (with a photon discharge helium ionization detector (PDHID)) to determine the gas concentration for the case of no sorption. After exposure to the sensing material, the gas concentration is again measured by the GC; this second measurement represents the amount of gas that did not sorb (residual gas). Therefore, by subtracting the residual analyte concentration from the initial concentration of the analyte, the amount of analyte sorbed can be calculated. The advantage of the highly specialized GC is that it can distinguish between similar analytes and record concentrations down to the ppb level. For each experimental run (before and after exposure to the sensing material), gas samples were collected at regular intervals (either every 12 minutes or every 20 minutes, depending on the gas analyte or gas analyte mixture) until readings 
remained consistent (this indicates that the system has reached equilibrium). Equilibrium for any given combination of a polymeric sensing material and a gas analyte (or gas analyte mixture) was typically achieved after $\sim 60$ minutes. Independent sampling replicates were performed for all samples.

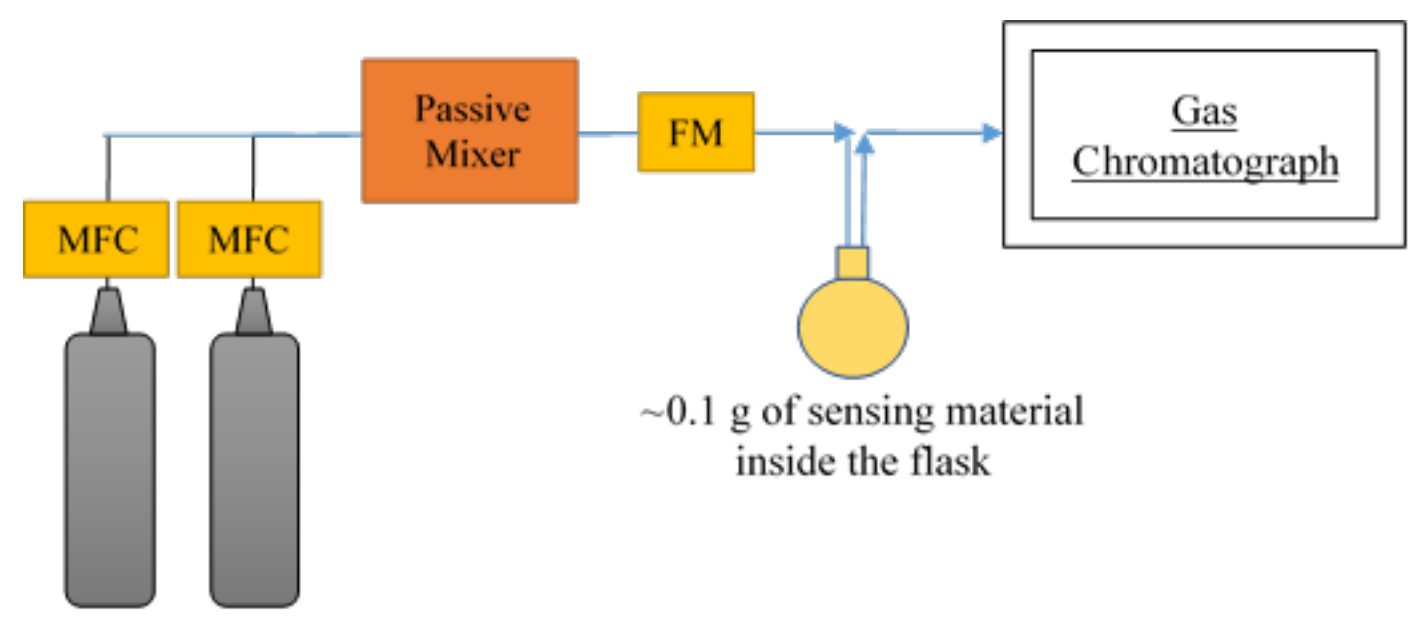

Figure 1. Experimental Set-Up for Evaluation of Sensing Materials, where MFC = Mass Flow Controller and FM = Flow Meter.

This experimental procedure was used to evaluate each material's affinity towards acetone: materials were exposed to 5 ppm acetone and the resulting sorption was recorded. This preliminary step made it possible to identify the most promising polymer backbones, dopants, and dopant levels. Once the most promising materials were identified, they were exposed to mixtures of four gas analytes (acetone with acetaldehyde, ethanol and benzene) to better understand each material's selectivity towards acetone. Exposing the sensing materials to several gases simultaneously makes it possible to observe the acetone sorption performance in the presence of other interferent gases; this is something that is rarely done in sorption studies, since sensing materials are typically exposed to individual analytes (one at a time).

\section{Results and Discussion}




\subsection{Acetone Sorption}

\subsubsection{Undoped Polymeric Materials}

The three undoped, unmodified polymer backbones are examined first. The sorption of polyaniline (PANI), polypyrrole (PPy) and poly(methyl methacrylate) (PMMA) after exposure to 5 ppm acetone is shown in Figure 2.

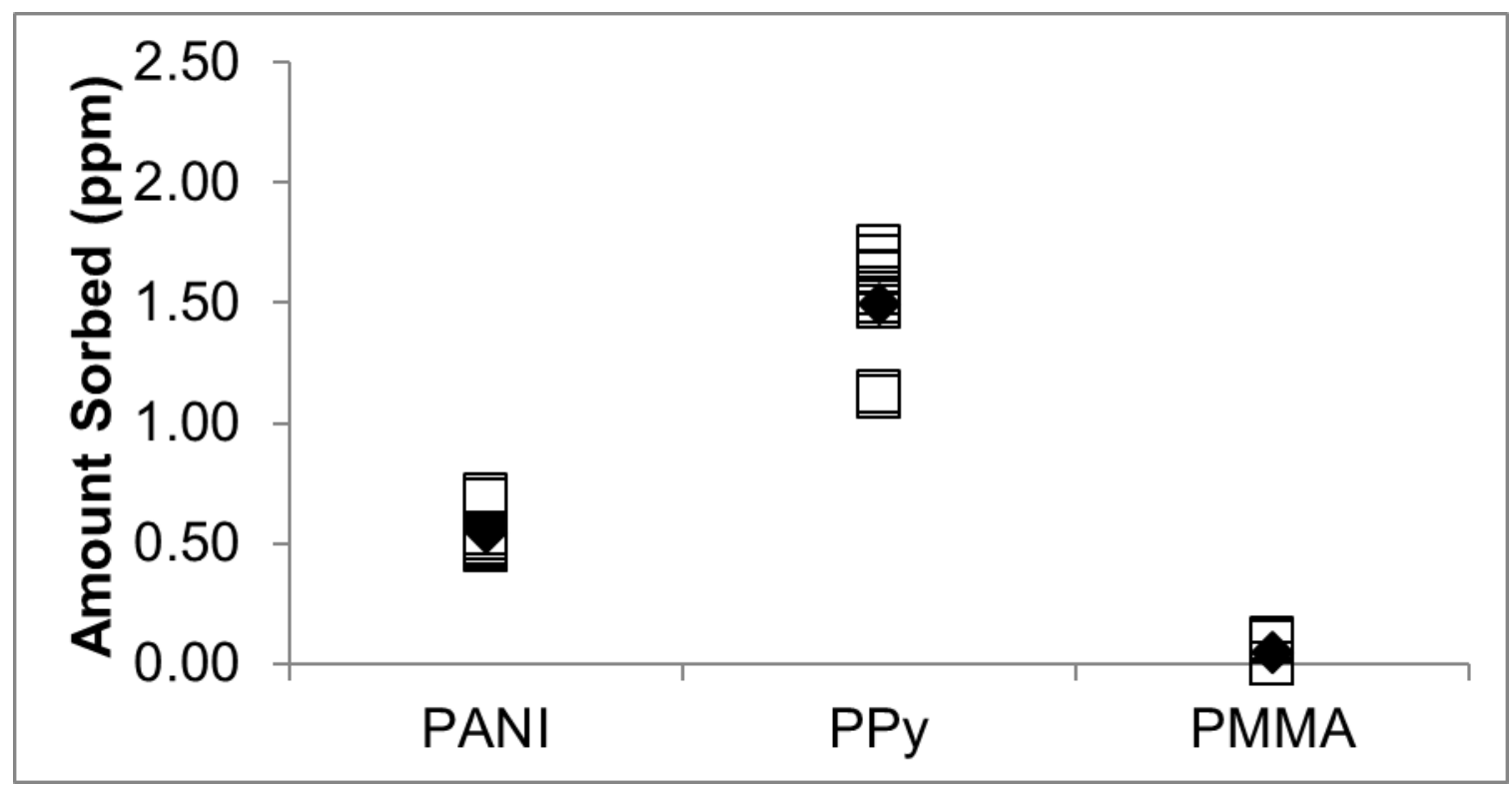

Figure 2. Acetone Sorption for PANI, PPy and PMMA (source: 5 ppm acetone in nitrogen);

$\square$ represents individual replicates and $\bullet$ represents the average sorption

The results of Figure 2 suggest that PPy allows for the most sorption, followed by PANI. In contrast, PMMA sorption is negligible. Although it is somewhat surprising that pure (undoped) PMMA was not an effective sensing material for acetone, it has frequently been used in combination with other comonomers (see, for example, these references ${ }^{[18-20,27,30,33]}$ ). 


\section{WILEY-VCH}

The sorption capability of the three materials can be related to the surface morphology of each polymer. SEM imaging (in Figure 3(a) and Figure 4(a)) shows that the PANI sample has many 'cavities' (well-dispersed throughout the sample), and the polymer itself exhibits a fibrous structure, which gives it a large surface area. Similarly, PPy samples are characterized by a large surface area due to the granular morphology (see Figure 3(b) and Figure 4(b)). In both cases, these structures resemble what happens when a catalyst particle accommodates a reaction within it that produces new material. This reaction can cause fragmentation of the (almost spherical) starting particle. This ‘explosion-fragmentation’ in turn creates a large fraction of interstitial space. In other words, more surface area is exposed and thus more area is available for whatever interactions can take place between the sensing material and the analyte in question. Hence, there are many sorption 'sites' available for an analyte (like acetone) to sorb (analogous to active sites in a catalytic system that can bind with adsorbing reactant molecules to lead to surface reaction and subsequently desorption of product molecules). Therefore, it makes sense that both PANI and PPy showed good sorption for acetone.

In contrast, Figure 3(c) and Figure 4(c) provide images of PMMA (at 500X and 5000X magnification, respectively). This is a different material altogether, compared to the other two morphologies discussed above. The image reveals a smooth 'plate-like' structure. This suggests that the sorption capability of this sample is limited, as the analyte may not sorb as easily to such a uniformly smooth material. Thus, the SEM images further support our sorption measurements: PANI and PPy have more surface area available (compared to PMMA), which is influencing the sorption capabilities. 


\section{WILEY-VCH}

(a)

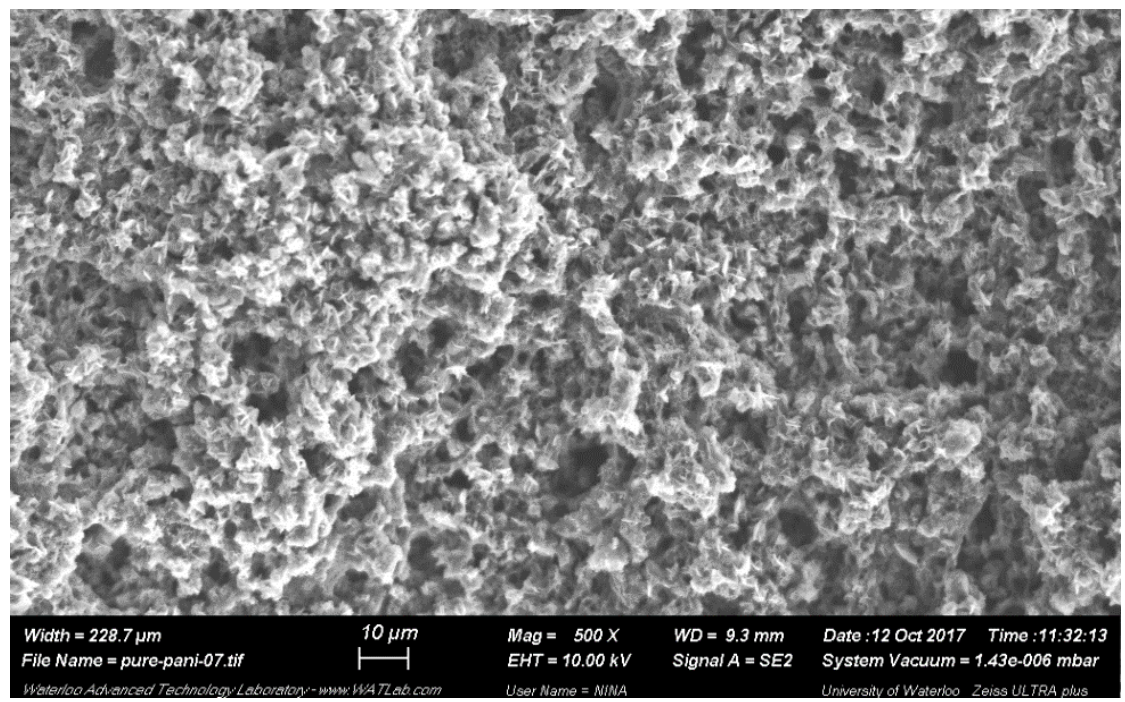

(b)

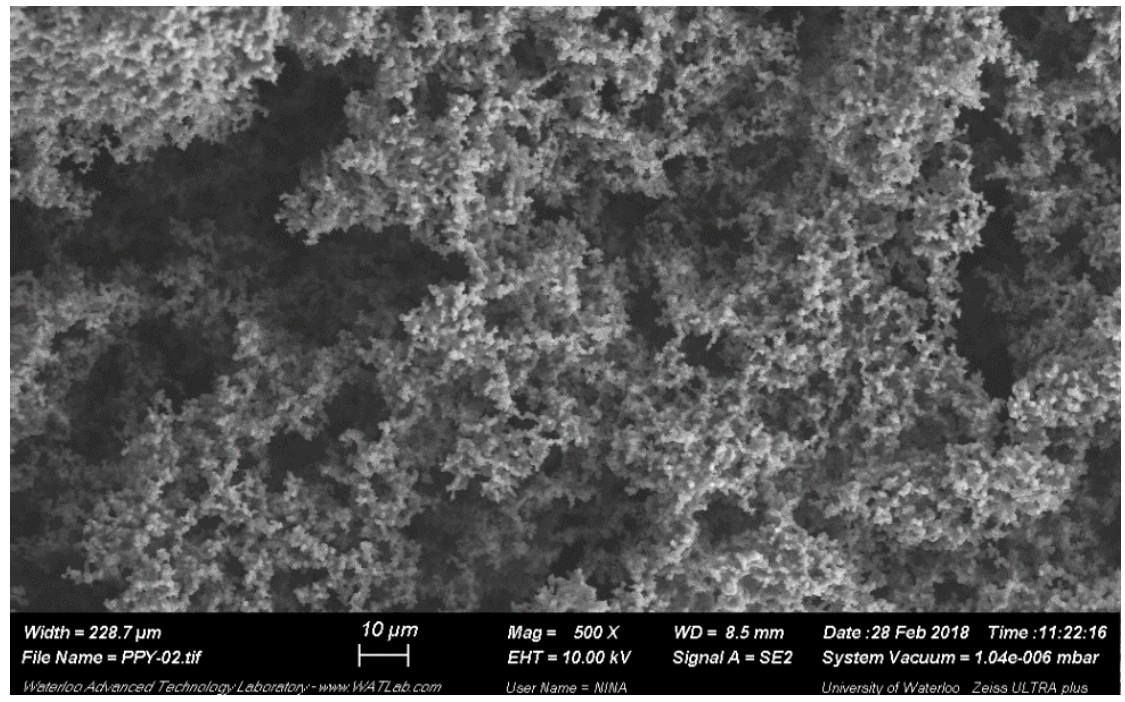

(c)

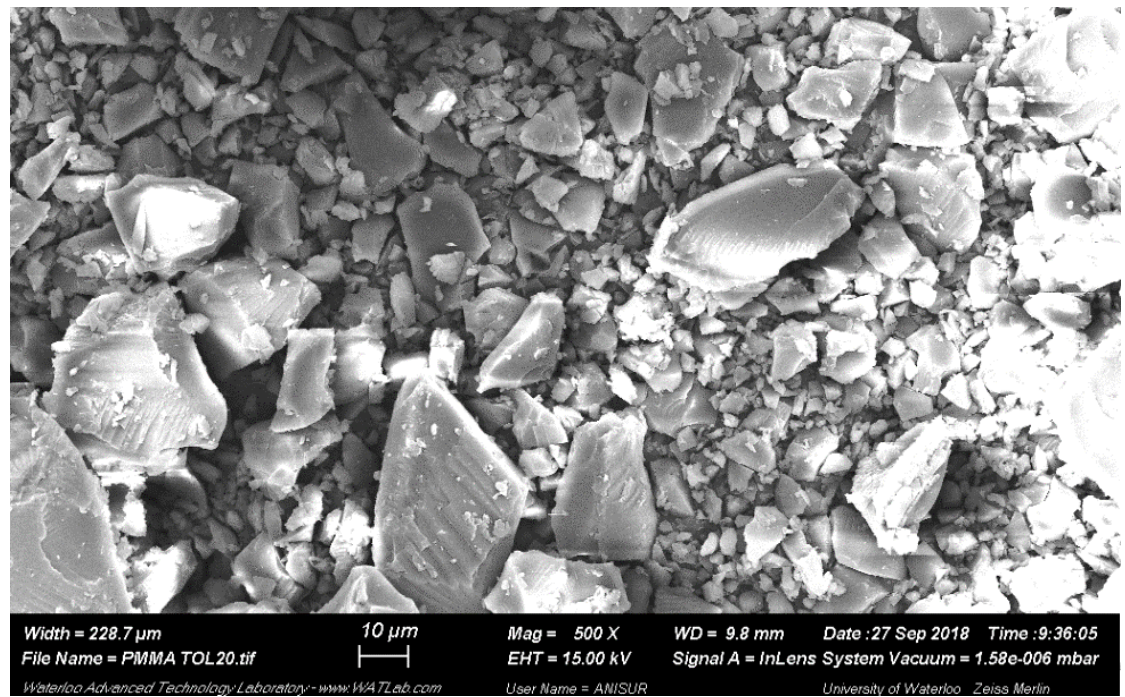

Figure 3. Surface Morphology of (a) PANI, (b) PPy and (c) PMMA from SEM at 500X

Magnification 


\section{WILEY-VCH}

(a)

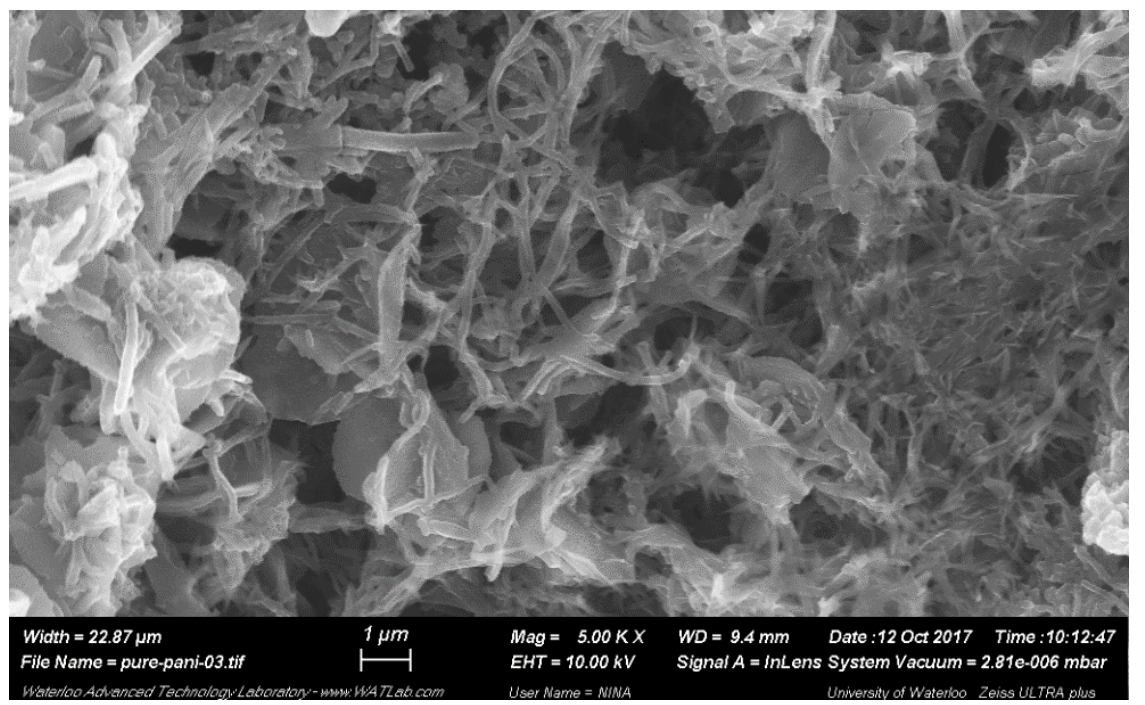

(b)

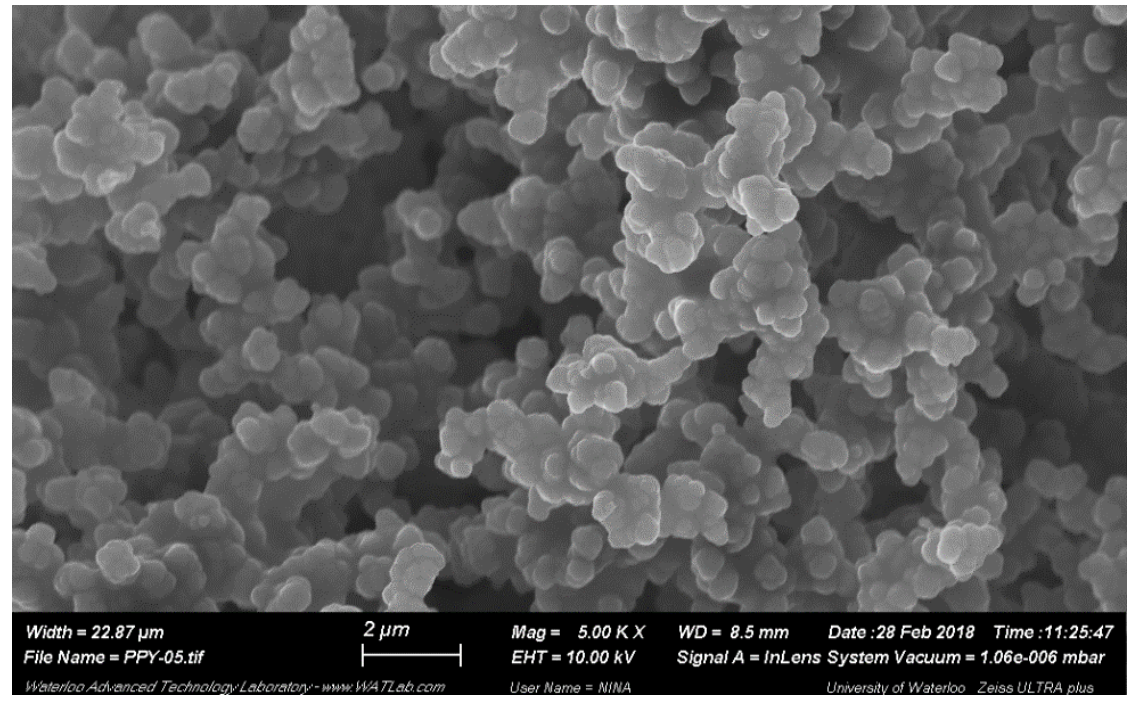

(c)

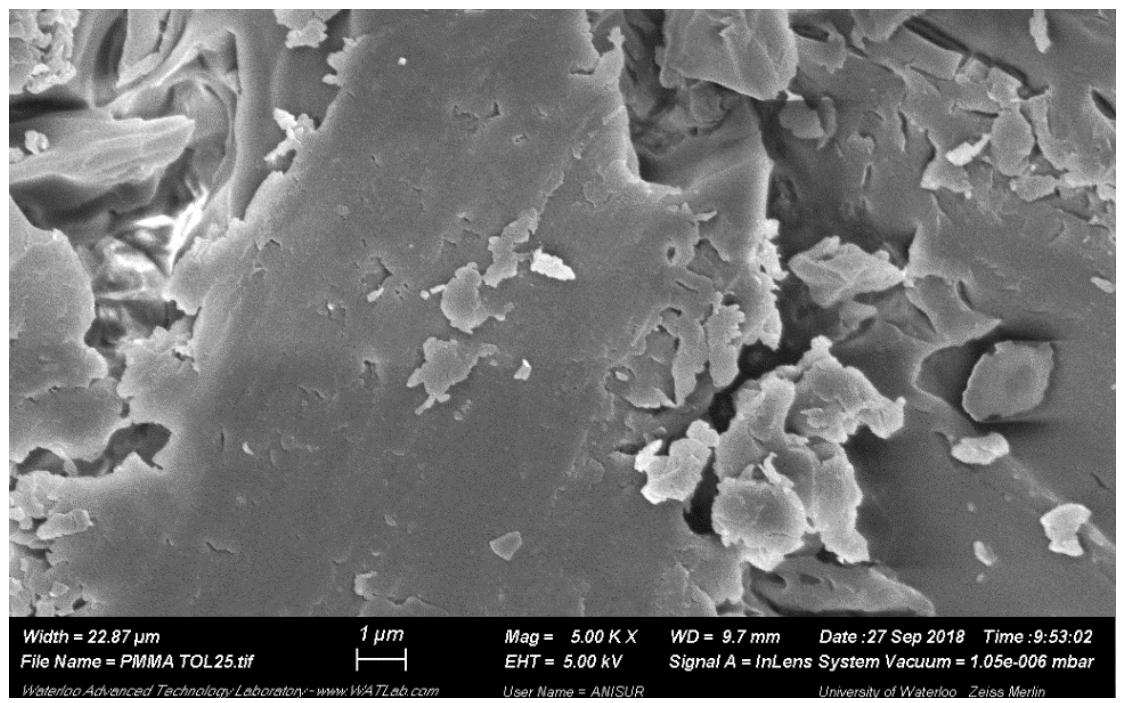

Figure 4. Surface Morphology of (a) PANI, (b) PPy and (c) PMMA from SEM at 5000X

Magnification 
Thus, based on these results, PANI and PPy show significantly more promise than PMMA. While PANI and PPy are more likely to be useful for acetone sensing, PMMA is still a material to keep in mind. PMMA can act as a substrate for metal oxides and it may also be useful as a 'zero baseline’ in future sensing (array) applications.

\subsubsection{Doped PANI Polymeric Materials}

The degree of incorporation of each metal oxide (as measured by EDX) is shown in Table 3; the final row of Table 3 will be discussed further in Section 4.1.3. All measurements took the full imaging area into account, which ensured that the result would be representative of the whole sample. Also, select replicate measurements were taken at different levels of magnification (typically ranging from 500X to 1000X) and showed good repeatability. Where more than one measurement was taken, averages are provided.

Table 3. Measured Metal Incorporation for Polymeric Materials

\begin{tabular}{|l|c|c|c|}
\hline \multirow{2}{*}{ Polymeric Nanocomposite } & \multicolumn{2}{|c|}{ wt \% of Metal (M) in Product Polymer } \\
\cline { 2 - 4 } & $\mathrm{SnO}_{2}$ & OO $_{3}$ & ZnO \\
\hline PANI w 5\% $\mathrm{MO}_{\mathrm{x}}$ & 7.00 & 0.22 & 0.10 \\
\hline PANI w $10 \% \mathrm{MO}_{\mathrm{x}}$ & 10.21 & 0.54 & 0.75 \\
\hline PANI w 20\% $\mathrm{MO}_{\mathrm{x}}$ & 19.57 & 0.77 & 0.94 \\
\hline PPy w 20\% $\mathrm{MO}_{\mathrm{x}}$ & 8.62 & 2.76 & 0.41 \\
\hline
\end{tabular}

These results indicate that of the three metal oxides investigated, only $\mathrm{SnO}_{2}$ incorporated readily into the PANI samples. Slight increases in W content and Zn content were observed for the other metal oxides (as the wt\% of the metal oxide increased in the recipe), but not by any appreciable amount. Interestingly, while the average measurements for $\mathrm{WO}_{3}$ were very low, targeted measurements (where metal oxides were clearly visible) showed much higher 


\section{WILEY-VCH}

concentrations of W. These 'spot' measurements for different formulations of PANI with $\mathrm{WO}_{3}$ ranged from $18.79 \mathrm{wt} \% \mathrm{~W}$ to $73.38 \mathrm{wt} \% \mathrm{~W}$, depending on the area selected. This (along with the SEM images) indicates that $\mathrm{WO}_{3}$ remains present in the polymer sample, but clumps together in large aggregates (compare Figure 5(c) and (d)).

Regardless of the degree of incorporation, the presence of the metal oxides during synthesis may affect the surface morphology of the product polymer. Therefore, representative SEM images are shown in Figure 5. Here, we can compare the pure (undoped) PANI morphology (Figure 5(a)) to the morphology of the materials doped with $10 \mathrm{wt} \%$ of each metal oxide (whether or not large amounts of the metal oxide remain in the final product).

(a)

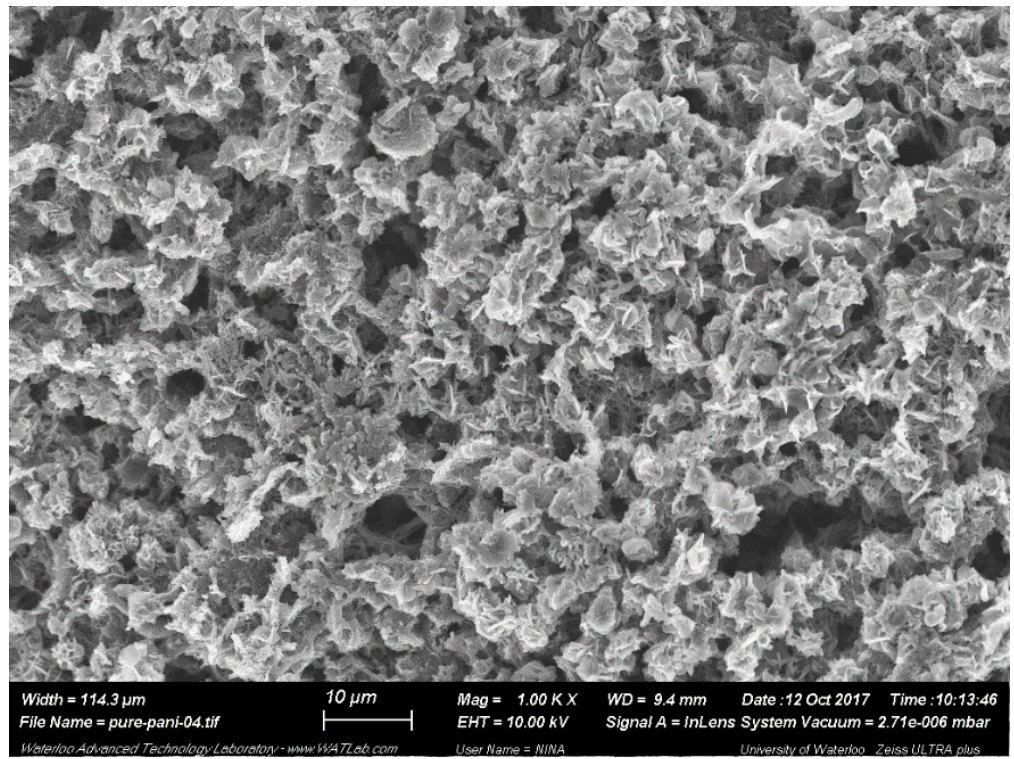




\section{WILEY-VCH}

(b)

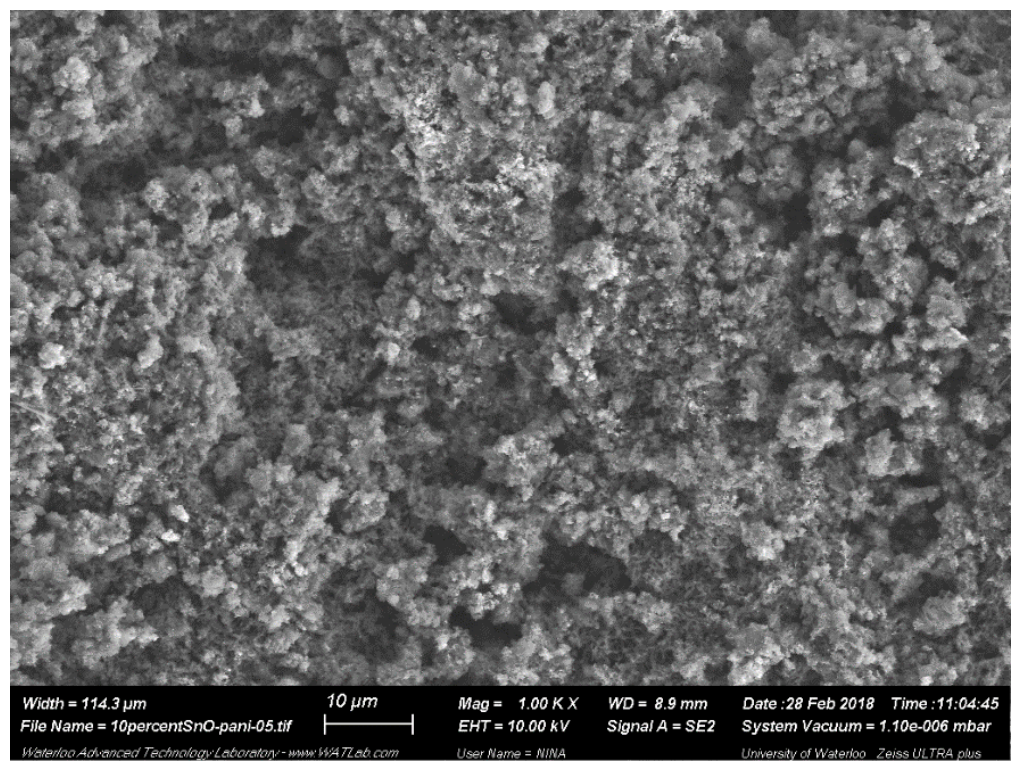

(c)

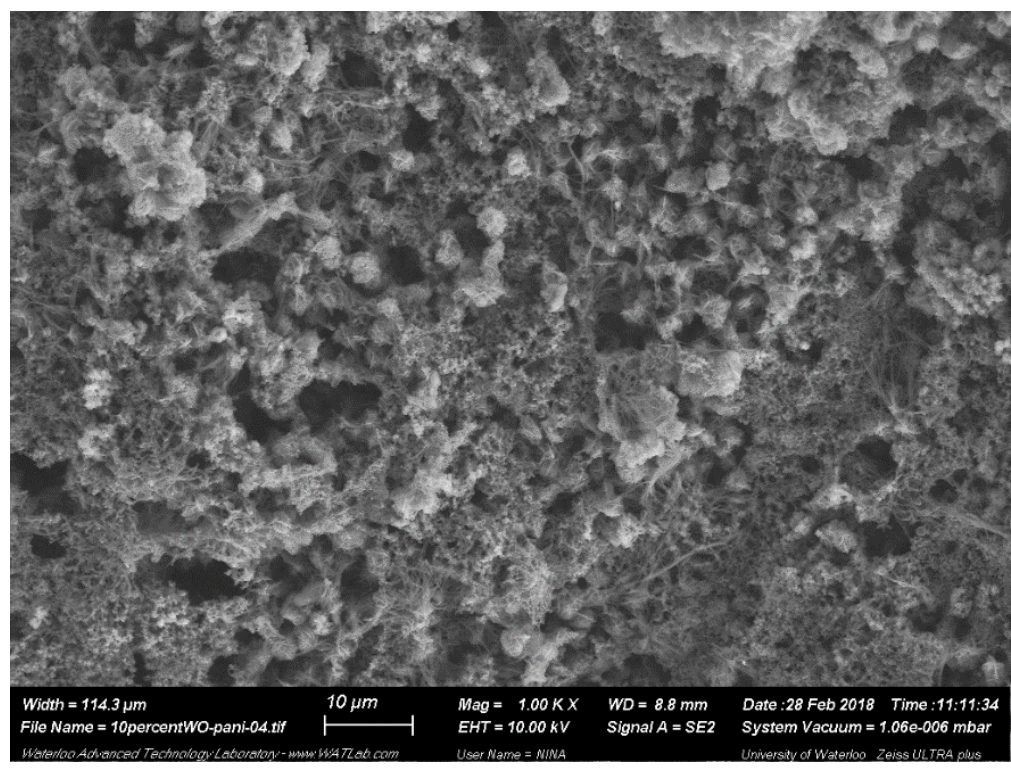

(d)

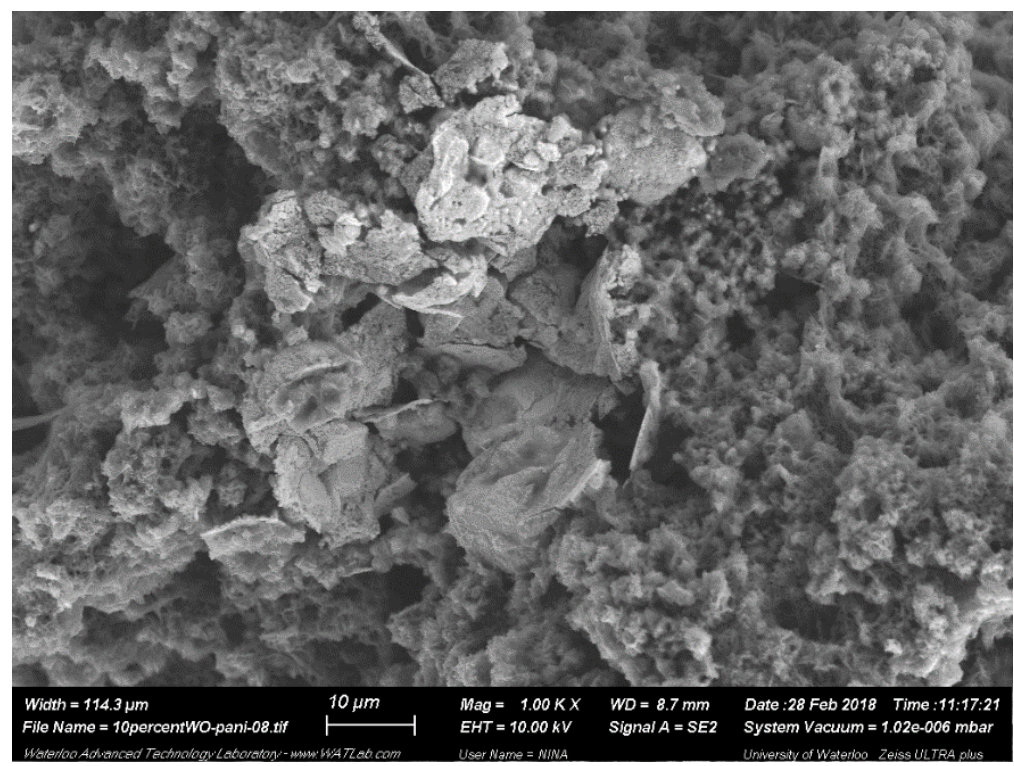




\section{WILEY-VCH}

(e)

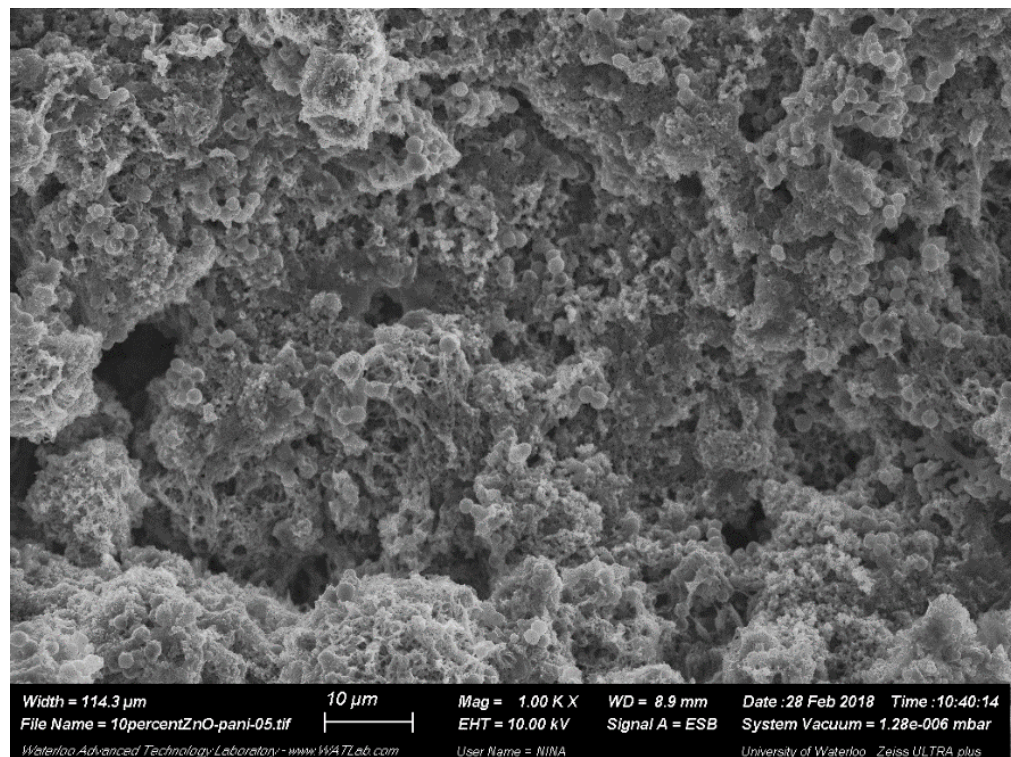

Figure 5. Surface Morphology of (a) PANI, (b) PANI doped with 10 wt\% SnO2, (c)

PANI doped with $10 \mathrm{wt} \% \mathrm{WO}_{3}$ (typical result), (d) PANI doped with $10 \mathrm{wt} \% \mathrm{WO}_{3}$

(metal oxide cluster), and (e) PANI doped with $10 \mathrm{wt} \% \mathrm{ZnO}$

Figure 5(b) is a representative image of $\mathrm{SnO}_{2}$-doped PANI. There are speckles visible throughout the sample, which indicates that the metal oxide particles are well-distributed (as expected, given the EDX results of Table 3). The underlying morphology is very similar to that of the pure PANI (contrast Figure 5(b) with Figure 5(a)).

Figure 5(c) and Figure 5(d) are both images of $\mathrm{WO}_{3}$-doped PANI. As discussed earlier, $\mathrm{WO}_{3}$ nanoparticles tend to form agglomerates during PANI synthesis, thus leaving the majority of the PANI part with little or no $\mathrm{WO}_{3}$. In Figure 5(c), the $\mathrm{WO}_{3}$ particles are non-existent. In contrast, Figure 5(d) (which is at the same magnification) is dominated by $\mathrm{WO}_{3}$ agglomerates. Where $\mathrm{WO}_{3}$ is absent (in Figure 5(c)), the PANI morphology is similar to the pure PANI morphology; one may argue that it has a slightly more granular morphology (which may be due to the presence of $\mathrm{WO}_{3}$ during synthesis). 


\section{WILEY-VCH}

Finally, we examine Figure 5(e). From EDX, we know that negligible quantities of ZnO are present in the sample. However, it seems as though the 'negative space' (or 'cavities') present in this sample is larger than in the pure PANI. It is possible that the presence of ZnO during synthesis has resulted in a slight deterioration of the morphology; ZnO nanoparticles may have prevented polymer growth in certain locations, only to be rinsed out following polymer synthesis.

Given these observations of the metal oxide effects on the surface morphology, we can now consider how acetone sorption performance has been affected. All sensing materials were exposed to 5 ppm acetone in balance nitrogen, and sorption was calculated as described previously.

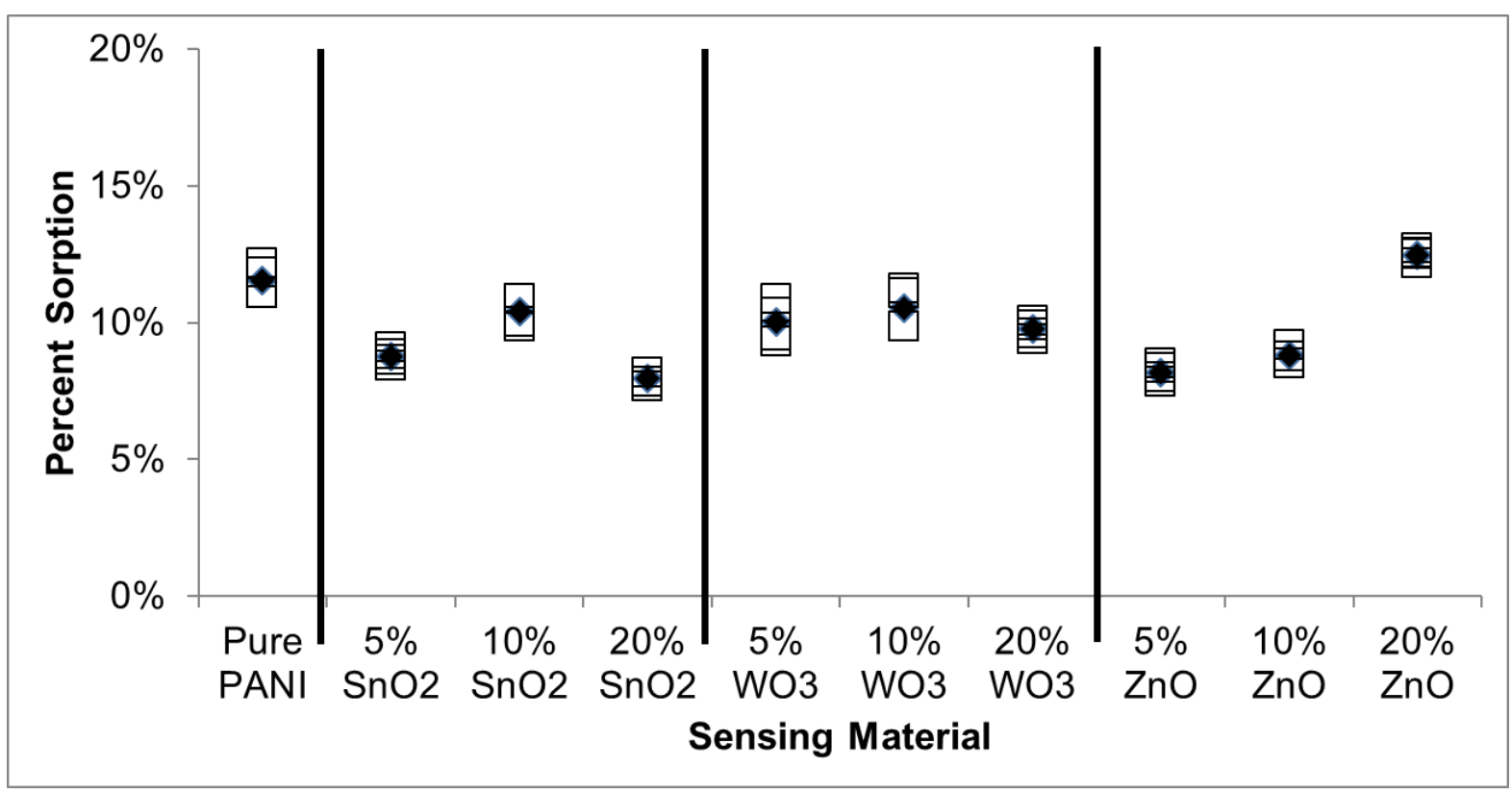

Figure 6. Acetone Sorption for PANI-based Polymeric Materials (source: 5 ppm acetone in nitrogen); $\square$ represents individual replicates and $\diamond$ represents the average sorption

Figure 6 indicates that doping PANI with any metal oxide shows little improvement in the sorption ability. Statistical comparison of means through Fisher's least significant difference 


\section{WILEY-VCH}

(LSD) test and multiple t-tests (with the Bonferroni correction applied) led to the following observations:

- For $\mathrm{SnO}_{2}$-doped materials, sorption averages at the three dopant levels were statistically different. PANI doped with $10 \% \mathrm{SnO}_{2}$ was found to be statistically better than the other $\mathrm{SnO}_{2}$-doped materials.

- For $\mathrm{WO}_{3}$-doped materials, there was no statistical difference between the percentage of acetone sorption at the three dopant levels. PANI doped with $5 \% \mathrm{WO}_{3}$ is preferred, since it uses the smallest amount of metal oxide and is therefore the least expensive option (if doping is used at all).

- For ZnO-doped materials, sorption averages at the three dopant levels were statistically different. PANI doped with $20 \% \mathrm{ZnO}$ was found to be statistically better than the other ZnO-doped materials.

\subsubsection{Doped PPy Polymeric Materials}

Given the limited incorporation of metal oxides for PANI (and the similar synthesis procedure used for PPy), the polymer properties are only evaluated for PPy doped with 20\% of each metal oxide. As shown in the last row of Table 3, $\mathrm{SnO}_{2}$ incorporates better than the other metal oxides, but the degree of incorporation is low for all three. Representative SEM images are shown in Figure 7; these can be contrasted with the pure PPy sample imaged at the same magnification, which was shown in Figure 3(b). 


\section{WILEY-VCH}

(a)

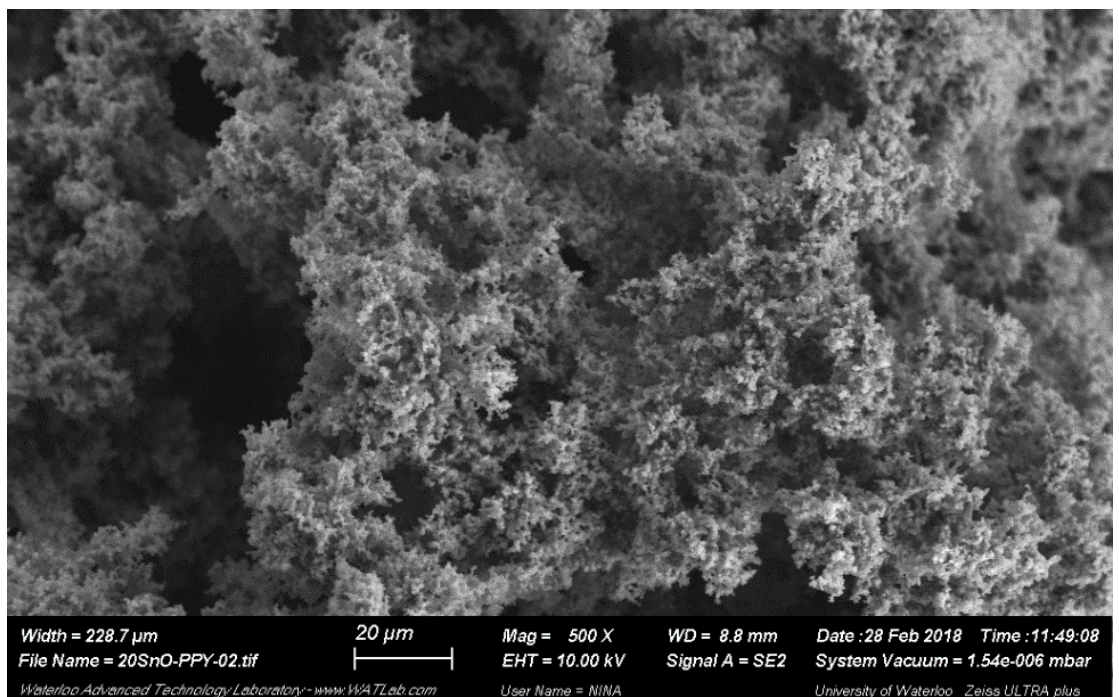

(b)

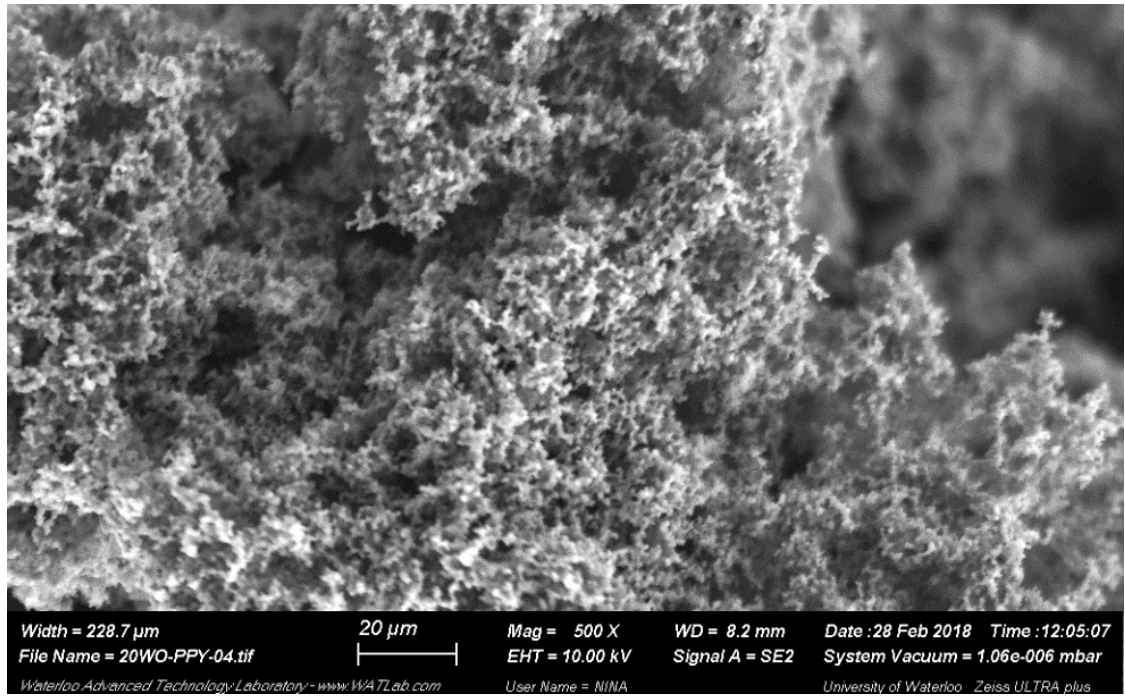

(c)

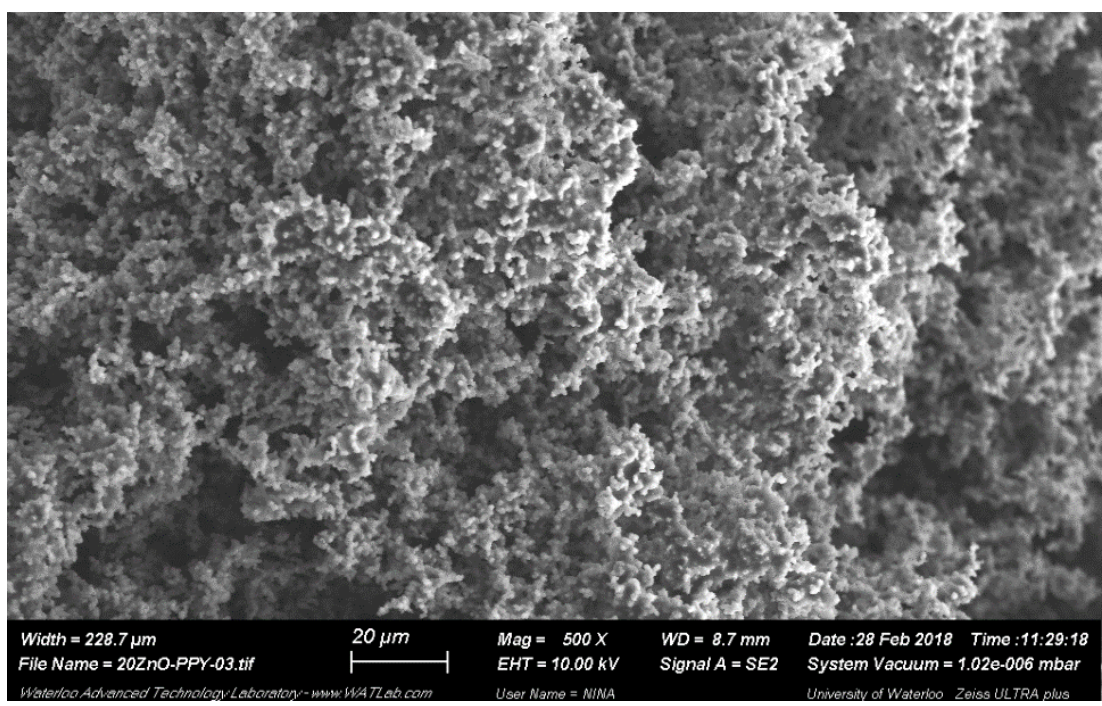

Figure 7. Surface Morphology of (a) PPy doped with $20 \mathrm{wt} \% \mathrm{SnO}_{2}$, (b) PPy doped with $20 \mathrm{wt} \% \mathrm{WO}_{3}$, and (c) PPy doped with $20 \mathrm{wt} \% \mathrm{ZnO}$ 


\section{WILEY-VCH}

The three images in Figure 7 are almost identical; the presence of metal oxides during synthesis (even at $20 \mathrm{wt} \%$ ) seems to have little effect on the PPy surface morphology. One might suggest that Figure 7(a) (PPy with 20\% $\mathrm{SnO}_{2}$ ) has more 'cavities' in the sample (compared to the other materials), but the general morphology is the same.

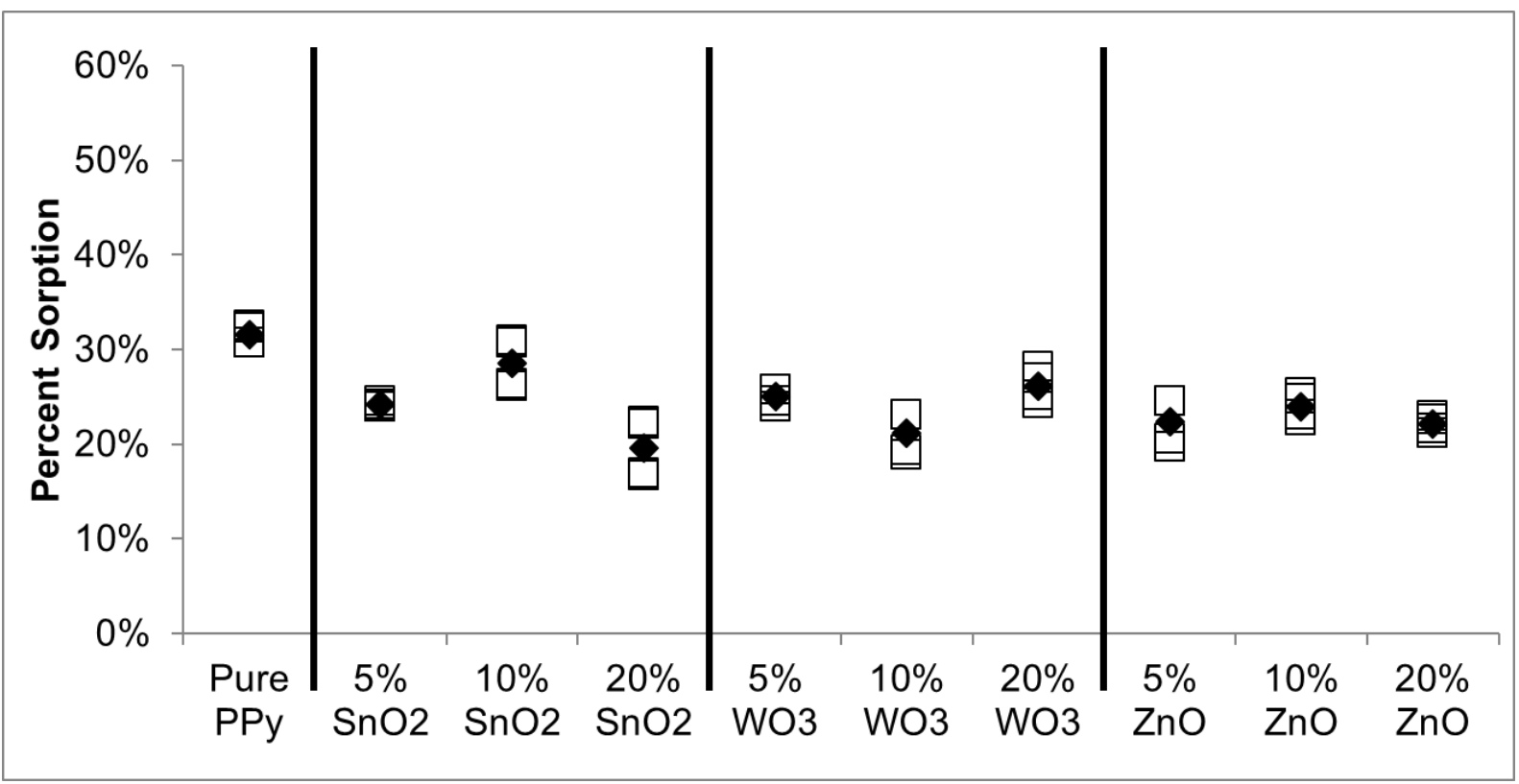

Figure 8. Acetone Sorption for PPy-based Polymeric Materials (source: 5 ppm acetone in nitrogen); $\square$ represents individual replicates and $\diamond$ represents the average sorption

In Figure 8, the sorption results are similar to those observed for PANI. Measurements were again compared using Fisher's LSD and multiple t-tests, and the results of the statistical analyses are summarized below:

- For $\mathrm{SnO}_{2}$-doped materials, all three dopant levels showed statistically significant differences in sorption. The best-performing material from this subset was PPy doped with $10 \% \mathrm{SnO}_{2}$.

- For $\mathrm{WO}_{3}$-doped materials, statistically significant differences in sorption were detected between $5 \%$ and $10 \%$, and between $10 \%$ and $20 \%$ dopant. In both comparisons, the $10 \% \mathrm{WO}_{3}$-doped material exhibited a lower percentage of sorption 


\section{WILEY-VCH}

and was therefore ruled out. However, no significant difference was observed in comparing the $5 \% \mathrm{WO}_{3} \mathrm{PPy}$ and the $20 \% \mathrm{WO}_{3} \mathrm{PPy}$. Therefore, for simplicity and to conserve resources, 5\% $\mathrm{WO}_{3} \mathrm{PPy}$ was selected.

- For ZnO-doped materials, no statistical difference was observed as the amount of dopant was varied. Therefore, PPy doped with 5\% $\mathrm{ZnO}$ is preferred, since it uses the least metal oxide.

\subsubsection{Doped PMMA Polymeric Materials}

In the case of PMMA-based materials, two separate and distinct components were visible in the samples. For example, in Figure 9, the smooth pieces to the left side of the image are PMMA, and the top right corner contains only $\mathrm{SnO}_{2}$ particles. Thus, incorporation was limited.

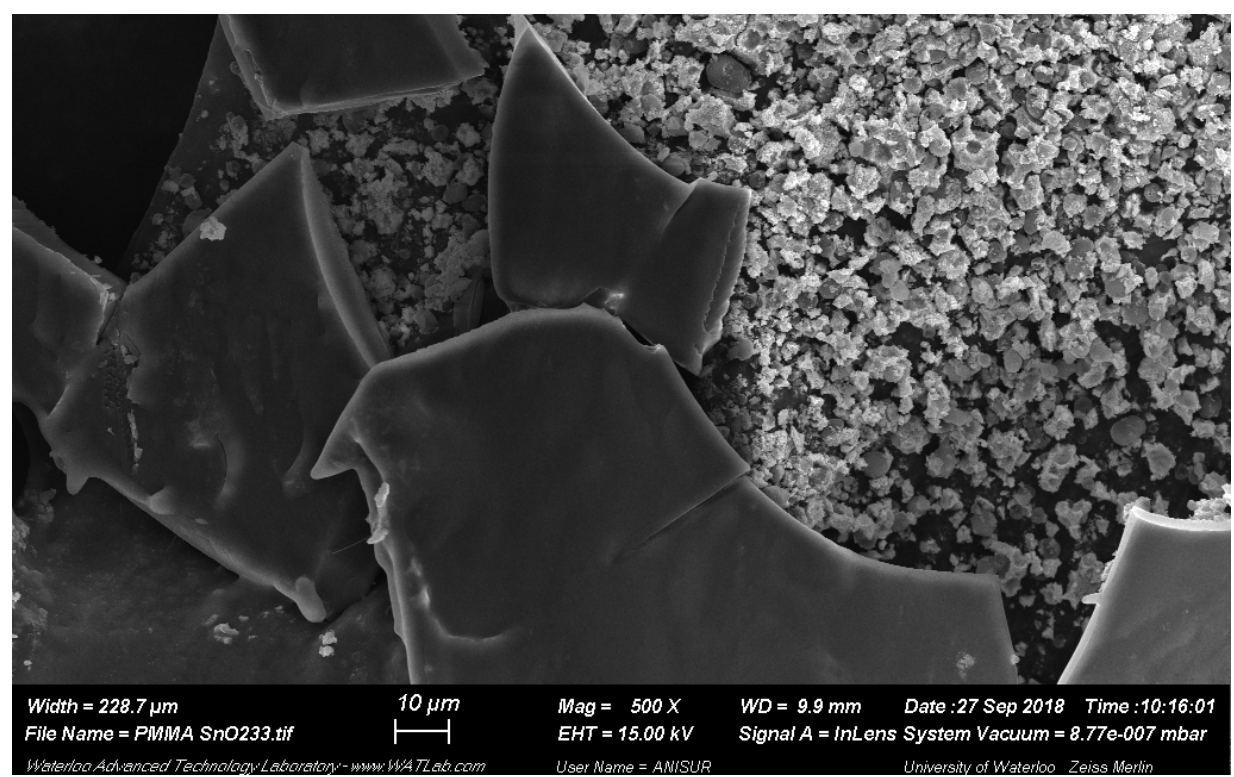

Figure 9. Surface Morphology of PMMA doped with $10 \mathrm{wt} \% \mathrm{SnO}_{2}$ 


\section{WILEY-VCH}

For all potential sensing materials that were PMMA-based, the amount of acetone sorbed was negligible. Additional modifications (including higher molecular weights of PMMA and in situ doping during in-house synthesis) were attempted, but similar results were obtained.

Although PMMA seems incapable of sorbing acetone under these conditions, the observed results are still useful for sensing applications. Zero-sorption materials can be used in sensors or sensor arrays to establish a baseline, which can help reduce the number of false positives in a sensing study. ${ }^{[4]}$ Therefore, this result, though negative with respect to the sorption capabilities of PMMA, can still inform future work, as it is useful in establishing a true zero.

\subsection{Selectivity - Mixtures of 4 Gases}

Eight polymeric sensing materials were used for this portion of the study: pure PANI, PANI with $10 \% \mathrm{SnO}_{2}$, PANI with 5\% $\mathrm{WO}_{3}$, PANI with $20 \% \mathrm{ZnO}$, pure PPy, PPy with $10 \% \mathrm{SnO}_{2}$, PPy with 5\% $\mathrm{WO}_{3}$ and PPy with 5\% ZnO. These materials, selected as 'most promising' from Section 4.1, either improved sorption in a statistically significant way (compared to other loadings of a given metal oxide) or, if no statistically significant improvement was observed, the lowest (and therefore most cost effective) metal oxide loading was selected.

\subsubsection{Gas Mixtures with Equal Concentrations of Analytes}

To establish each polymeric material's ability to sorb acetone in the presence of other interferent gases, each material was exposed to a 4-gas mixture containing acetaldehyde, ethanol, acetone and benzene (in balance nitrogen). These analytes were specifically chosen as representatives of different volatile organic compounds, so that the sorption of acetone could be measured in the presence of interfering aldehydes, alcohols and aromatics. The 


\section{WILEY-VCH}

concentration of each gas in the mixture was $0.9 \mathrm{ppm} \pm 0.1 \mathrm{ppm}$, and the total concentration of analytes in the gas mixture ranged from $3.3 \mathrm{ppm}$ to $4.0 \mathrm{ppm}$. Therefore, we are sorbing from a slightly less concentrated gas mixture than for the pure acetone study, and there are several analytes competing for sorption sites. This is essentially mimicking a 'healthy breath' scenario; endogenous volatile organic compound concentrations should generally be fairly low. As reported by Rooth and Ostensen, ${ }^{[46]}$ the breath acetone levels for a control group averaged $0.95 \mathrm{ppm}$ (although healthy levels reported by Jones were as high as $4.01 \mu \mathrm{g} / \mathrm{L}(3.46$ $\mathrm{ppm})$ ). ${ }^{[4]}$ The other gas analytes are also expected to be present in low quantities (assuming the subjects are healthy and no exogenous factors are contributing). Jones reported typical acetaldehyde breath concentrations ranging from $0.2 \mathrm{nmol} / \mathrm{L}$ to $0.6 \mathrm{nmol} / \mathrm{L}$ ( $7.6 \mathrm{ppb}$ to 22.8 ppb), with higher levels after the moderate consumption of alcohol. ${ }^{[48]}$ Higher levels of ethanol have been reported, again by Jones: breath ethanol measurements ranged from 0.07 to $0.39 \mu \mathrm{g} / \mathrm{L}$ (60.3 ppb to $336 \mathrm{ppb})$ when no exogenous alcohol was consumed. ${ }^{[47]}$ Finally, benzene is not expected to be present in breath samples in any appreciable amount (unless the subject is a smoker ${ }^{[49]}$ or has had substantial environmental exposure ${ }^{[50]}-$ these levels are beyond the scope of this work). However, benzene was selected for inclusion in the current study to examine the sorption effects of aromatic compounds and because benzene is a typical 'bulky’ interferent. 


\section{WILEY-VCH}

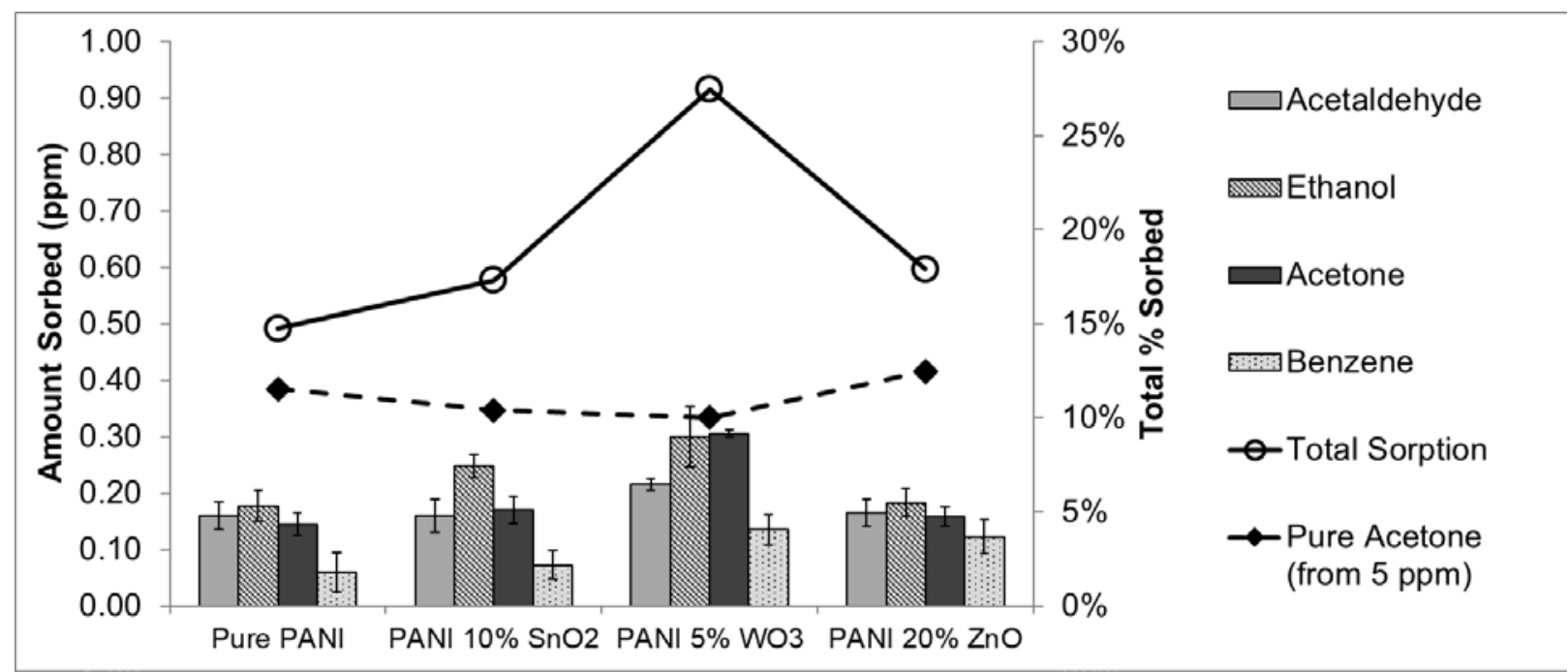

Figure 10. Sorption of Acetaldehyde, Ethanol, Acetone and Benzene for PANI-based Polymeric Materials (source: 1 ppm each analyte in nitrogen)

Figure 10 shows the sorption results for each of the most promising PANI-based materials (pure PANI and one representative sample for each of the metal oxides). The bar graph provides the average amount of each analyte sorbed, and is presented in terms of absolute concentration sorbed (in ppm) rather than the (normalized) percent sorption of earlier plots (since we are looking at very low concentrations here). In parallel, the line graph provides a comparison of the total percentage sorbed for the combination of analytes and the percentage of acetone sorbed from the 5 ppm source (described earlier for the sensitivity study).

For all PANI-based materials, acetaldehyde, ethanol and acetone show similar amounts of sorption. This information can help to establish a baseline for a 'negative' result (that is, breath acetone levels are normal and are not indicative of high blood glucose). Only PANI with $5 \% \mathrm{WO}_{3}$ sorbs acetone in the highest proportion, but statistically speaking there is no difference in sorption between ethanol and acetone. Therefore, none of these PANI-based materials would be used in isolation to sorb low concentrations of acetone (in the presence of these interferents), but they may be useful as part of a sensor array. ${ }^{[51]}$ 


\section{WILEY-VCH}

The comparison of line plots in Figure 10 ('Total Sorption' and 'Pure Acetone (from 5 ppm)' shows an increase in the percentage of analyte sorption for the 4-gas mixture compared to pure acetone at 5 ppm. This is especially evident for the $\mathrm{WO}_{3}$-doped PANI, which allowed 27.5\% sorption (compared to $10.0 \%$ sorption for acetone alone). For the 4-gas mixture, both the ethanol sorption and the acetone sorption were fairly high; one might suggest that the presence of ethanol is enhancing acetone sorption (or vice versa), thus increasing the overall analyte sorption. This result highlights the importance of exposing potential sensing materials to several gases simultaneously, since using mixtures of gases can help to identify interactions between different gas analytes as they sorb onto polymeric sensing materials.

Next, we examine the selectivity of the most promising PPy-based materials (again, with representative samples doped with each of the three metal oxides). The sorption of each analyte in the 4-gas mixture (acetaldehyde, ethanol, acetone and benzene) is presented in the bar graph portion of Figure 11, while the total percentage of sorption (from 5 ppm pure acetone and from the 4-gas mixture) is shown as a line graph.

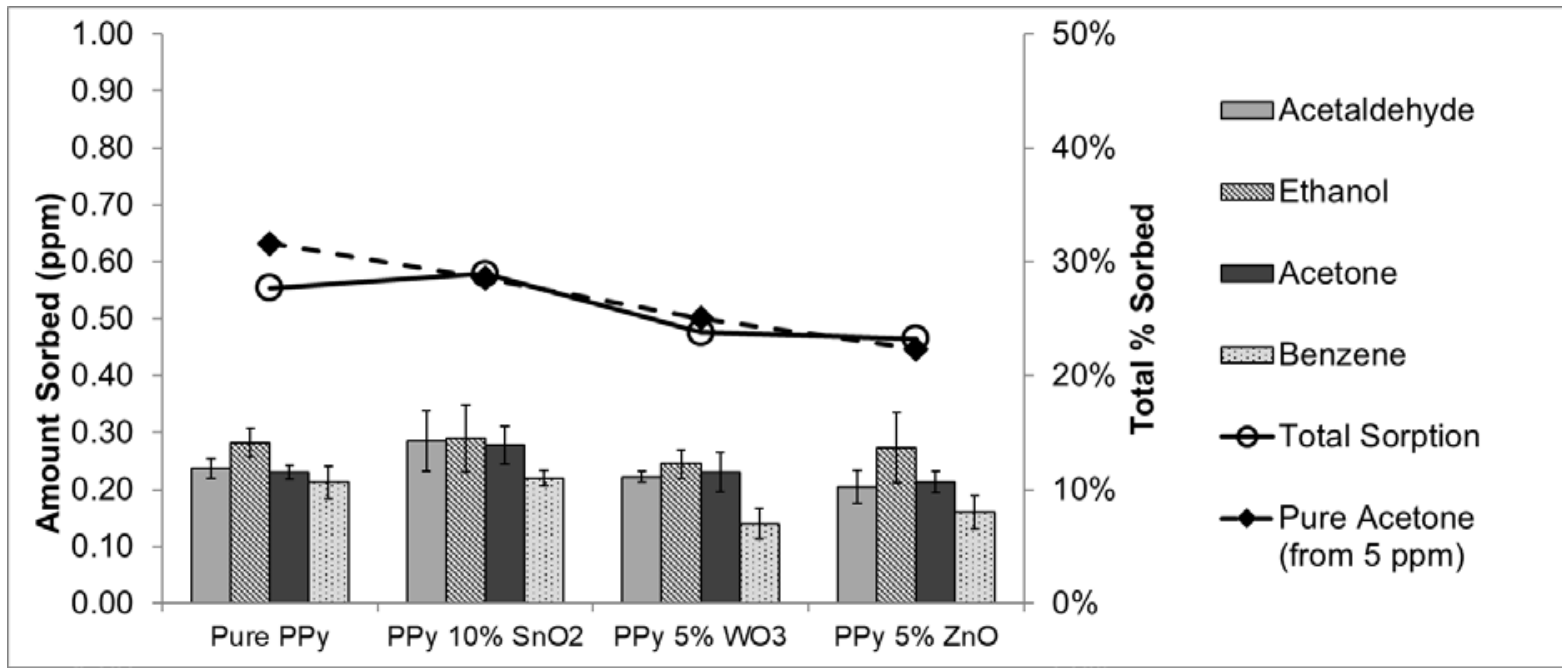




\section{WILEY-VCH}

Figure 11. Sorption of Acetaldehyde, Ethanol, Acetone and Benzene for PPy-based Polymeric Materials (source: 1 ppm each analyte in nitrogen)

Again (as we observed for the PANI-based materials), there is no appreciable selectivity towards acetone. The more interesting result for PPy-based materials is related to the comparison of line graphs for total sorption of the 4-gas mixture and the total sorption of 5 ppm acetone (from the sensitivity study). As shown in Figure 11, the two sets of experiments provide nearly identical sorption results. That is, regardless of whether the PPy-based sensing materials are exposed to pure acetone (at $5 \mathrm{ppm}$ ) or a mixture of gas analytes (totaling $\sim 4$ ppm), the proportion of gas analytes sorbed remains approximately consistent. This suggests that polypyrrole (and metal oxide-doped polypyrrole samples) are indiscriminately sorbing all analytes, and that the materials are not selective towards any particular chemical species. Thus, these polymers may not be useful for detecting one particular target analyte, but could be useful in a sensor array or as a material for air filtration applications.

\subsubsection{Acetone-Rich (A-rich) Gas Mixtures}

For the final stage of this investigation, we can increase the acetone concentration in the gas mixture, thus creating an acetone-rich gas mixture (with acetaldehyde, ethanol and benzene present as interferents). Although the exact (expected) concentration of acetone varies considerably in biological studies, we chose to use a relatively high acetone concentration. As proof of concept, PANI-based materials and PPy-based materials were exposed to a 4-gas mixture of acetaldehyde (1.3 ppm $\pm 0.1 \mathrm{ppm})$, ethanol (1.3 ppm $\pm 0.2 \mathrm{ppm})$, acetone (105 $\mathrm{ppm} \pm 5 \mathrm{ppm})$ and benzene (1.4 ppm $\pm 0.2 \mathrm{ppm})$. 


\section{WILEY-VCH}

For brevity, only the sorption response of pure PANI and pure PPy are shown herein; similar results were obtained for the metal oxide-doped materials. A comparison of sorption performance for the gas mixtures where all analytes had similar concentration levels (labeled '1 ppm Gas Mixture’) and the acetone-rich (A-rich) gas mixtures is provided in Figure 12.

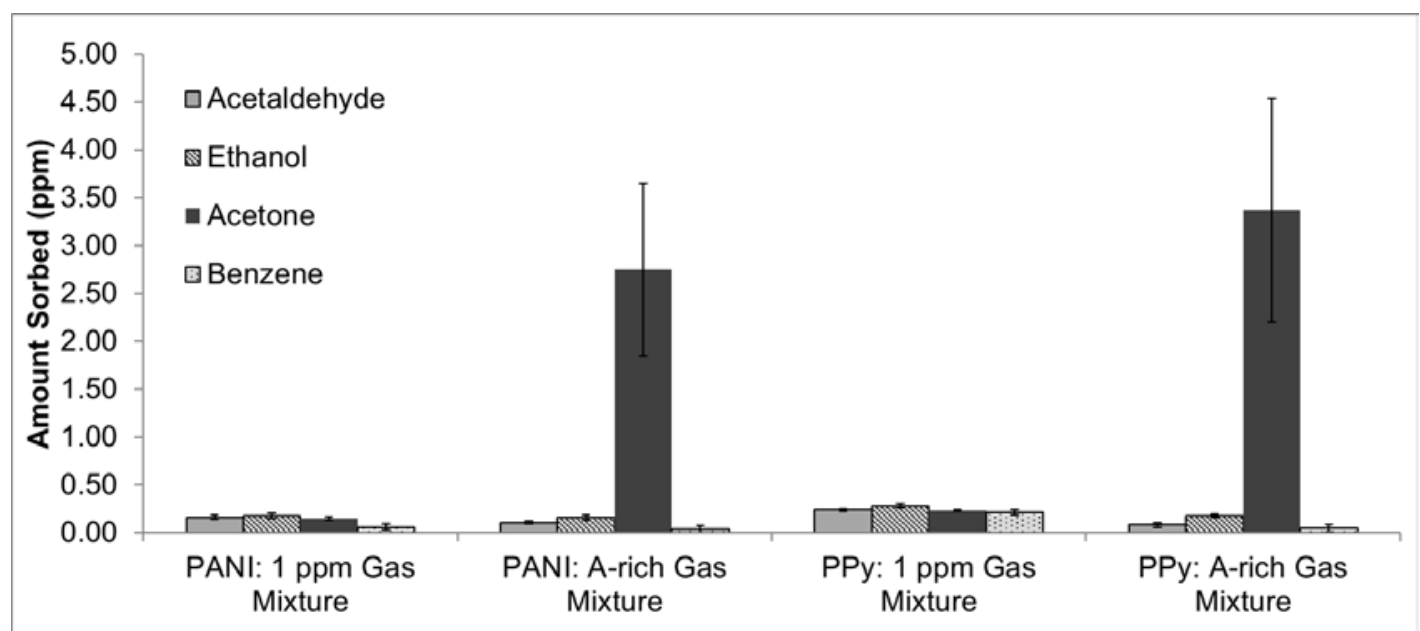

Figure 12. Sorption of Acetaldehyde, Ethanol, Acetone (A) and Benzene for Pure PANI and Pure PPy (source: 1 ppm each analyte in nitrogen or A-rich gas mixture)

The 'PANI: 1 ppm Gas Mixture’ and the 'PPy: 1 ppm Gas Mixture’ data have been shown previously (in Figures 10 and 11, respectively), but are shown again herein for direct comparison (and to appreciate the scale of sorption of the acetone-rich gas mixtures). A clear increase in acetone sorption is visible for both pure PANI and pure PPy, which is expected given the significant increase in acetone exposure. In both acetone-rich (A-rich) cases, we see much wider error bars (representative of standard deviation over 6 replicates), but this is due to the larger absolute value of the measurements (especially compared to the non-dominant analytes: acetaldehyde, ethanol and benzene).

While these acetone-rich sorption results do not represent true selectivity measurements, they provide insight about how such sensing materials perform when acetone is present in much 


\section{WILEY-VCH}

larger concentrations than other interfering gases. Both PANI and PPy show promise as sensing materials for acetone detection under such conditions; however, a better understanding of acetone levels in breath measurements would be needed to quantify the anticipated ratio of acetone to interferents in the source gas.

\section{Conclusions}

In pursuit of simple polymeric materials for acetone sensing, polyaniline, polypyrrole and poly(methyl methacrylate) were doped with varying levels of metal oxide nanoparticles (namely $\mathrm{SnO}_{2}, \mathrm{WO}_{3}$ and $\mathrm{ZnO}$ at 5\%, 10\% and 20\% doping by weight). In spite of the low incorporation of metal oxides, PANI-based materials and PPy-based materials were found to be the most promising candidates. PMMA-based materials did not show significant sorption, and metal oxide doping did not improve PMMA sorption under the experimental conditions used for this study.

In comparing the polymer surface morphology to the sorption ability, we would suggest that the materials with the more porous structures sorb more acetone (PPy > PANI > PMMA). However, even the most porous materials lack selectivity. For PPy, for example, exposure to 5 ppm acetone (in nitrogen) or a mixture of 4 different gas analytes (with the total concentration $\sim 5 \mathrm{ppm}$ ) led to the same total proportion of analytes sorbed. Therefore, the polypyrrole samples indiscriminately sorb all analytes, and the material is not selective towards any of the four chemical species.

Although the reported selectivity is low, the experimental evaluation process should be noted: researchers rarely consider the impact of several gases coexisting at the sensing site. This type of selectivity study should be performed more frequently, especially in evaluating polymeric 


\section{WILEY-VCH}

sensing materials. In this work, selectivity studies were performed using a custom-made gas testing system, and polymeric sensing materials were exposed to four gas analytes (acetone and three interferent gases) simultaneously. When all four analytes were present in equal concentrations, none of the materials could preferentially sorb acetone. However, given an acetone-rich gas mixture, acetone sorption was much increased.

\section{Acknowledgements}

The authors wish to thank former undergraduate (senior design project) students P.J. Panchal and T.K. Sivakumaran for their assistance with synthesizing and analyzing PANI and $\mathrm{WO}_{3}-$ doped PANI. Thanks also to A. Shepherd (at the time, an undergraduate co-op student from USA) for his assistance during the preliminary stages of the polypyrrole study. Additionally, the authors wish to acknowledge financial support from the Natural Sciences and Engineering Research Council (NSERC) of Canada and the Canada Research (CRC) program (AP). Special thanks to UWW/OMNOVA Solutions, USA, for special support to AJS.

Received:

Revised:

Published online:

\section{References}

[1] International Diabetes Federation, IDF Diabetes Atlas, ninth ed., Brussels, Belgium, 2019. Available at: http://diabetesatlas.org

[2] C. Turner, Expert Rev. Mol. Diagn. 2011, 11, 497.

[3] Z. Wang, C. Wang, J. Breath Res. 2013, 7, 037109.

[4] N. Makisimovich, V. Vorotyntsev, N. Nikitina, O. Kaskevich, P. Karabun, F. Martynenko, Sens. Actuators B. 1996, 35, 419.

[5] P. Sahay, J. Mater. Sci. 2005, 40, 4383.

[6] L. Mazeina, F. Perkins, V. Bermudez, S. Arnold, S. Prokes, Langmuir. 2010, 26, 13722.

[7] M. Righettoni, A. Tricoli, S. Pratsinis, Analy. Chem. 2010, 82, 3581.

[8] M. Righettoni, A. Tricoli, S. Gass, A. Schmid, A. Amann, S. Pratsinis, in The 14th International Meeting on Chemical Sensors, Nuremberg, May 2012.

[9] M. Righettoni, A. Schmid, A. Amann, S. Pratsinis, J. Breath Res. 2013, 7, 037110.

[10] J. Shin, S. Choi, I. Lee, D. Youn, C. Park, J. Lee, H. Tuller, I. Kim, Adv. Funct. Mater. 2013, 23, 2357.

[11] Y. Zhang, W. He, H. Zhao, P. Li, Vacuum. 2013, 95, 30.

[12] S. Choi, I. Lee, B. Jang, D. Youn, W. Ryu, C. Park, I. Kim, Anal. Chem. 2012, 85, 1792. 


\section{WILEY-VCH}

[13] S. Choi, F. Fuchs, R. Demadrille, B. Grevin, B. Jang, S. Lee, J. Lee, H. Tuller, I. Kim, ACS Appl. Mater. Interfaces. 2014, 6, 9061.

[14] S. Choi, B. Jang, S. Lee, B. Min, A. Rothschild, I. Kim, ACS Appl. Mater. Interfaces. 2014, 6, 2588.

[15] C. Shao, Y. Chang, Y. Long, Sens. Actuators B. 2014, 204, 666.

[16] Y. Xiao, L. Lu, A. Zhang, Y. Zhang, L. Sun, L. Huo, F. Li, ACS Appl. Mater. Interfaces. 2012, 4, 3797.

[17] D. Zhang, A. Liu, H. Chang, B. Xia, RSC Adv. 2015, 5, 3016.

[18] S. Russell, D. Weinkauf, Polymer. 2001, 42, 2827.

[19] L. Ruangchuay, A. Sirivat, J. Schwank, Talanta. 2003, 60, 25.

[20] B. Philip, J. Abraham, A. Chandrasekhar, V. Varadan, Smart Mater. Struct. 2003, 12, 935.

[21] B. Landini, S. Bravard, IEEE Sens. J. 2009, 9, 1802.

[22] J. Yu, H. Byun, M. So, J. Huh, Sens. Actuators B. 2005, 108, 305.

[23] Z. Ying, Y. Jiang, H. Qin, L. Zheng, X. Du, COMPEL Journal. 2010, 29, 477.

[24] M. Frank, K. Moon, S. Kassegne, Smart Mater. Struct. 2010, 19, 035015.

[25] S. Vaddiraju, K. Gleason, Nanotechnology. 2010, 21, 125503.

[26] S. Nath, M. Choudhury, D. Chakdar, G. Gope, R. Nath, Sens. Actuators B. 2010, 148, 353.

[27] J. Do, S. Wang, Sens. Actuators B. 2013, 185, 325.

[28] N. Hausmann, M. Meredith, S. Minteer, ECS Trans. 2013, 45, 1.

[29] T. Nasution, I. Nainggolan, S. Hutagalung, K. Ahmad, Z. Ahmad, Sens. Actuators B. 2013, 177, 522.

[30] A. Daneshkhah, S. Shrestha, M. Agarwal, K. Varahramyan, in Smart Biomedical and Physiological Sensor Technology XI, Baltimore, May, 2014.

[31] W. Chen, K. Stewart, R. Mansour, A. Penlidis, in IEEE MTT-S International Microwave Symposium, Phoenix, May, 2015.

[32] A. Daneshkhah, S. Shrestha, M. Agarwal, K. Varahramyan, Sens. Actuators B. 2015, 221, 635.

[33] S. Devikala, P. Kamaraj, M. Arthanareeswari, Mater. Today: Proc. 2019, 14, 271.

[34] G. Korotcenkov, Mater. Sci. Eng., B. 2007, 139, 1.

[35] D. McQuade, A. Pullen, T. Swager, Chem. Rev. 2000, 100, 2537.

[36] K. M. E. Stewart, N. T. McManus, E. Abdel-Rahman, A. Penlidis, J. Macromol. Sci. Part A Pure Appl. Chem. 2012, 49, 1.

[37] K. M. E. Stewart, A. Penlidis, Macromol. Symp. 2013, 324, 11.

[38] K. M. E. Stewart, A. Penlidis, Macromol. Symp. 2016, 360, 123. 


\section{WILEY-VCH}

[39] K. M. E. Stewart, A. Penlidis, Polym. Adv. Tech. 2016, 133, 319.

[40] E. A. Grulke, in Polymer Handbook, $3^{\text {rd }}$ Edition (Eds: J. Brandrup, E. Immergut), John Wiley \& Sons, Inc., New York 1989, pp. VII/519.

[41] L. Shacklette, C. Han, in MRS Proceedings, Vol. 328, 1993.

[42] D. van Krevelen, K. te Nijenhuis, in Properties of Polymers: Their Correlation with Chemical Structure; their Numerical Estimation and Prediction from Additive Group Contributions, Elsevier, 2009, pp. 201-222.

[43] F. Bradner, J. Shapiro, H. Bowley, D. Gerrard, W. Maddams, Polymer, 1989, 30, 914.

[44] K. Stewart, W. Chen, R. Mansour, A. Penlidis, J. Appl. Polym. Sci. 2015, 132, 42259.

[45] H. K. Chitte, N. V. Bhat, V. E. Walunj, G. N. Shinde, J. Sens. Tech. 2011, 1, 47.

[46] G. Rooth, S. Ostenson, The Lancet, 1966, 288, 1102.

[47] A. W. Jones, J. Anal. Toxicol. 1985, 9, 246.

[48] A. W. Jones, Alcohol Alcohol. 1995, 30, 271.

[49] L. Wallace, E. Pellizzari, T. Hartwell, R. Perritt, R. Ziegenfus, Arch. Environ. Health. 1987, 42, 272.

[50] M. A. G. Wallace, J. D. Pleil, K. D. Oliver, D. A. Whitaker, S. Mentese, K. W. Fent, G. P. Horn, J. Occup. Environ. Hyg. 2019, 16, 355.

[51] K. M. E. Stewart, A. J. Scott, A. Penlidis, Polym. Adv. Tech. In Press. 


\section{WILEY-VCH}

\section{Table of Contents Entry}

Polymeric sensing materials for acetone detection have the potential to be used in diabetesrelated applications. However, prior work in the area reports extremely complex synthesis procedures. Polyaniline, polypyrrole, and poly(methyl methacrylate)) (with and without metal oxide-doping) are easily synthesized, and their performance as acetone sensing materials is evaluated herein. Polyaniline and polypyrrole appear promising.

\section{Sensing Materials}

A. J. Scott, N. Majdabadifarahani, K. M. E. Stewart, T. A. Duever, A. Penlidis*

Straightforward Synthesis and Evaluation of Polymeric Sensing Materials for Acetone Detection

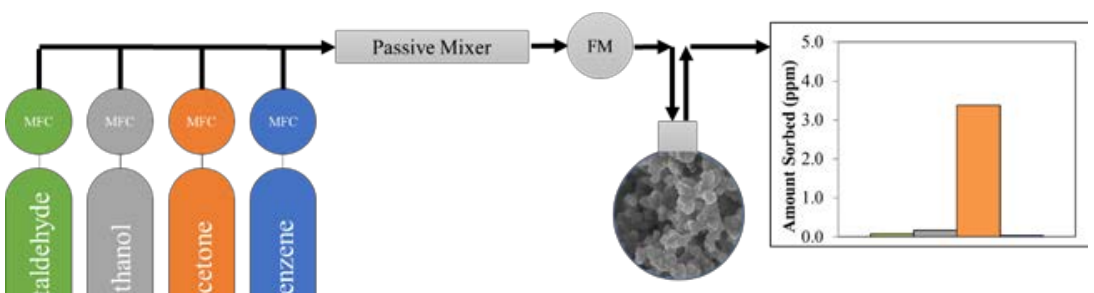

